\title{
Scale-out of Microreactor Stacks for Portable and Distributed Processing: Coupling of Exothermic and Endothermic Processes for Syngas Production
}

\author{
Matthew S. Mettler, ${ }^{\dagger}$ Georgios D. Stefanidis, ${ }^{\dagger,+}$ and Dionisios G. Vlachos, ${ }^{* \dagger}$ \\ Department of Chemical Engineering and Center for Catalytic Science and Technology (CCST), University of \\ Delaware, 150 Academy Street, Newark, Delaware 19716, and Intensified Reactions and Separation Systems, \\ Process \& Energy Department, Delft University of Technology, Leeghwaterstraat 44, 2628 CA Delft, The Netherlands
}

\begin{abstract}
Computational fluid dynamics (CFD) simulations are used to simulate stacks of different sizes, to understand nonlinear effects that arise in scaleout of microchemical systems. As an example process, syngas production from methane is studied using a multifunctional, parallel-plate reactor with alternating combustion and steam reforming channels. A scale-out strategy is proposed that creates larger stacks from a base unit. Stacks are evaluated in terms of efficiency, maximum wall temperature, and stability under external heat loss for both high and moderate wall thermal conductivities. We find that smaller stacks are unstable under laboratory heat-loss conditions. Stacks with high wall thermal conductivities are more stable than those with moderate wall conductivities under our conditions. At high heat-loss coefficients, significant transverse thermal gradients exist between interior and edge channels of the stacks that result in a significant loss of efficiency. A transition from all ignited to some ignited and extinguished and finally to all extinguished channels is discovered as criticality is approached in moderate size stacks. Microsystems provide 1-3 orders of magnitude larger volumetric and gravimetric throughputs than conventional technology, irrespective of model uncertainty, and such intensification is central to portable and distributed processing. They exhibit energy efficiency that is a strong function of size and heat loss but can outperform conventional processing under many conditions. However, they result in higher cost per unit syngas volume unless system optimization is performed.
\end{abstract}

\section{Introduction}

Microreactors have gained widespread attention in application areas, such as catalyst and drug testing, portable power generation, and chemical production. For many industrial processes, there can be significant advantages in replacing conventional large-scale reactors with microreactors. ${ }^{1-14}$ Small length scales, characteristic of microreactors, can render processes safer. ${ }^{3}$ The submillimeter distances enhance heat transfer and minimize hot-spot formation. ${ }^{4,7,14}$ This is desirable in highly exothermic processes as well as systems where isothermal conditions are needed. In the unfortunate event of an explosion or chemical release, lower hold-up volumes within microreactors can reduce the magnitude of any harmful impact. ${ }^{2,4,5}$ Syntheses involving hazardous chemicals have been demonstrated many years ago using microreactors by researchers at DuPont. ${ }^{5}$ Finally, for processes where production rates are limited by transport, microtechnology can lead to drastic reductions in equipment sizes with a concomitant reduction in capital cost and enhanced energy efficiency. ${ }^{1,4,6-8,10-12,15}$

The small size of microreactors inherently limits the quantity of product that may be produced from a single channel. To meet the demand for a chemical product in the marketplace, microreactor units are "scaled-out" or "numbered-up" to form larger stacks. Several scale-out issues, such as stack fabrication ${ }^{16}$ and flow distribution, ${ }^{17-19}$ have been addressed in the literature. One issue that has not been evaluated is how laboratory throughput rates and performance scale with the number of channels. In published experimental work, a single microreactor stack size

* To whom correspondence should be addressed. Tel.: (302) 8312830. Fax: (302) 831-1048. E-mail: vlachos@udel.edu.

Department of Chemical Engineering and Center for Catalytic Science and Technology (CCST), University of Delaware.

₹ Intensified Reactions and Separation Systems, Process \& Energy Department, Delft University of Technology. is studied and is thought to be representative of larger process unit behavior (e.g., see refs 11 and 20). This is done to reduce costs, because the fabrication of stacks is time-consuming and expensive. Literature microreactor stack models are developed with a similar philosophy. Full microreactor stacks have been modeled by Schouten and co-workers, ${ }^{21}$ using a simplified reactor model and assuming uniform fluid and metal temperatures in the direction perpendicular to the microstructured plate and instantaneous hydrogen combustion on the burner side. Usually, a small number of channels are simulated to minimize computational cost. Generally, models use periodic boundary conditions (see Figure S-1 in the Supporting Information) to essentially study an infinite stack (with no edges). ${ }^{8,12,22,23}$

To connect literature modeling and experimental work to the commercial scale, designers assume that all channels in a stack behave similarly and, therefore, production increases linearly with the number of channels in a stack. The linear scale-out model is illustrated in Figure 1 for methane and methanol steam reforming (SR), taken here as an example for distributed and portable energy generation. As a result of the linear scale-out assumption, many authors conclude that numbering-up microreactor stacks makes for an easier transition from technical development to real-world application than conventional scaleup. 4,5,8,11,12,20,23,24 The number of channels needed varies considerably with application (see Figure 1).

The linear scale-out model may break down, because it has not been established that physical phenomena caused by stack edges affect all channels equally. To the best of our knowledge, the effect of stack edges on scaling-out microreactor stacks has not been studied in the literature. This work makes the first stride in determining the effects of scaling-out microreactor stacks for an example process: methane SR. Using computational fluid dynamics (CFD), stacks of different sizes are simulated to study effects from scaling-out parallel plate reactors consisting of alternating catalytic combustion (CC) and SR channels. Ef- 


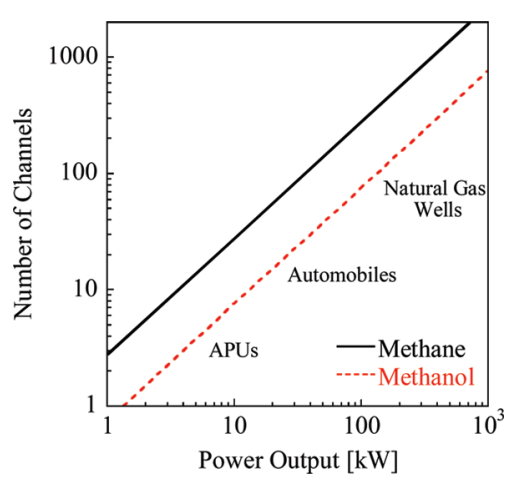

Figure 1. Stack size as a function of power output based on a linear scaleout model. Methanol and methane reforming data is taken from recent work ${ }^{43}$ using an infinite stack geometry (see Supporting Information). The scale-out calculations assume a stack width (dimension into the page, Figure $\mathrm{S}-1$ schematic) of $10 \mathrm{~cm}$, which is equal to the reported channel length. Setting the channel width equal to length minimizes the external surface area to volume ratio of the stack and limits external heat losses. (APU stands for auxiliary power unit.)

ficiency, stability, temperature, and conversion data are used to evaluate stacks under varying degrees of external heat loss in the first part of the paper. Comparison of the performance of the microreactors stacks to conventional methane steam reformers, based on volume, efficiency, catalyst weight, and catalyst cost indices, comprises the second part.

\section{Methane Steam Reforming (SR)}

Methane SR has received attention recently, because it is the first step in converting natural gas to liquid fuels or hydrogen for fuel cells. The importance of this comes from the desire to transition from traditional transportation power based on petroleum to renewable energy or in utilizing remote and offshore natural gas resources.

Industrial steam reformers are large, with methane throughputs typically on the order of $100000 \mathrm{~N} \mathrm{~m}^{3} / \mathrm{h}$. Methane SR and water-gas-shift (WGS) reactions generally take place in multiple packed-bed tubular reactors operated in parallel and encompassed by methane-fired furnaces. ${ }^{25}$ These reactors usually operate with low effectiveness factors, because of the interparticle heat transfer limitations in the catalyst bed. ${ }^{26}$ Overall reactions for the process are:

$$
\begin{gathered}
\mathrm{CH}_{4}+2 \mathrm{O}_{2} \rightarrow 2 \mathrm{H}_{2} \mathrm{O}+\mathrm{CO}_{2} \quad \Delta H_{\mathrm{Rxn}}=-803 \mathrm{~kJ} / \mathrm{mol} \\
\mathrm{CH}_{4}+\mathrm{H}_{2} \mathrm{O} \rightarrow 3 \mathrm{H}_{2}+\mathrm{CO} \quad \Delta H_{\mathrm{Rxn}}=206 \mathrm{~kJ} / \mathrm{mol} \\
\mathrm{CO}+\mathrm{H}_{2} \mathrm{O} \rightarrow \mathrm{H}_{2}+\mathrm{CO}_{2} \Delta H_{\mathrm{Rxn}}=-41 \mathrm{~kJ} / \mathrm{mol}
\end{gathered}
$$

Because microreactors substantially reduce transport limitations, significant benefit is gained by replacing the conventional nickel-based SR in fixed-bed catalysts with a high activity rhodium-based one in parallel-plate microreactors. This intensification step yields a 2-orders-of-magnitude reduction in reactor size $\mathrm{s}^{8,10,13}$ and facilitates the use of methane for on-board hydrogen production ${ }^{13}$ and remote natural gas conversion to syngas and then to liquid fuels. ${ }^{27}$

\section{Model}

3.1. Computational Fluid Dynamics (CFD) Modeling. Two-dimensional (2D) microreactor stack geometries were simulated using the CFD software package FLUENT and meshes were generated in GAMBIT software. ${ }^{28}$ The third dimension (width) is assumed to be long enough, compared to the stack height, to ensure $2 \mathrm{D}$ validity. In all simulations, 40 nodes/cm are used in the axial direction and 670 and 750 nodes/ $\mathrm{cm}$ were used in the transverse direction for combustion and SR channels, respectively. Because walls have small thermal gradients, only 100 transverse nodes/cm were used in this domain to reduce simulation time. Prior to performing these calculations, simulation results for a reactor with the above grid were compared to an identical reactor with double the number nodes (transverse and axial), to confirm grid independence. A first-order upwind discretization scheme is used for momentum, species, and energy equations. All under-relaxation factors are set to FLUENT default values ( 0.7 for momentum and 1 for species equations), except for the energy equation, which is varied between 0.985 and 0.995 . Simulations are considered converged when all relative residuals are $<10^{-9}$ and stable (i.e., minimal oscillation). Catalytic surface reaction rates for methane combustion on $\mathrm{Pt} / \mathrm{Al}_{2} \mathrm{O}_{3}$ and $\mathrm{SR}$ and WGS on $\mathrm{Rh} / \mathrm{Al}_{2} \mathrm{O}_{3}$ were input as boundary conditions at the channel-wall interfaces as seen in Figure 2. Single-step rate expressions for these reactions are taken from recently published kinetics derived from microkinetc modeling and contain coverage-dependent activation energies. $^{29,30}$ The equations describing the rates are

$$
\begin{gathered}
r_{\mathrm{CH}_{4}}^{\mathrm{comb}}=\operatorname{SAF}_{\mathrm{Pt}}\left[\frac{\gamma_{6} c_{\mathrm{CH}_{4}}}{\left(1+\gamma_{7} \sqrt{c_{\mathrm{O}_{2}}}\right)^{2}}\right] \\
r_{\mathrm{CH}_{4}}^{\mathrm{sr}}=\mathrm{SAF}_{\mathrm{Rh}}\left[\frac{\gamma_{4} c_{\mathrm{CH}_{4}}}{\left(1+\gamma_{1} \sqrt{c_{\mathrm{H}_{2}}}\right)\left(1+\gamma_{2} \sqrt{c_{\mathrm{H}_{2}}}+\gamma_{3} c_{\mathrm{CO}}\right)^{2}}\right]\left(1-\eta_{\mathrm{sr}}\right) \\
r^{\mathrm{wgs}}=\operatorname{SAF}_{\mathrm{Rh}}\left[\frac{\gamma_{5} c_{\mathrm{H}_{2} \mathrm{O}}}{\left(1+\gamma_{2} \sqrt{c_{\mathrm{H}_{2}}}+\gamma_{3} c_{\mathrm{CO}}\right)^{2}}\right]\left(1-\eta_{\mathrm{wgs}}\right)
\end{gathered}
$$

The rate parameters $\left(\gamma_{i}\right)$ in the above equations represent combinations of elementary reaction rate constants taken from microkinetic models. ${ }^{29,30}$ The activation energy for methane adsorption on platinum is taken to be $10 \mathrm{kcal} / \mathrm{mol}$ for consistency with previous work. ${ }^{8}$ Surface area factors for platinum $\left(\mathrm{SAF}_{\mathrm{Pt}}\right)$ and rhodium $\left(\mathrm{SAF}_{\mathrm{Rh}}\right)$ catalysts are used to relate the effective catalytic surface area, which lumps the effect of active sites and diffusion within the supported catalyst, to the geometric surface area of the channel wall. The general definition for SAF is

$$
\mathrm{SAF}=\frac{\text { effective catalyst surface area }}{\text { geometric surface area }}
$$

This definition for SAF implies that an increase in weight loading of a catalyst does not necessarily induce a linear increase in reaction rate. The SAF value for supported platinum is $1.7^{31}$ and for rhodium is 1.0 , for consistency with previous work. ${ }^{8,13}$ To account for the thermodynamic limitations of SR and WGS reactions, the approach to equilibrium $(\eta)$ is used. For the SR process, the approach to equilibrium is defined as

$$
\eta_{\mathrm{sr}}=\frac{K_{\mathrm{sr}}}{K_{\text {equilibrium,sr }}}
$$

where

$$
K_{\mathrm{sr}}=\frac{P_{\mathrm{H}_{2}}^{3} P_{\mathrm{CO}}}{P_{\mathrm{CH}_{4}} P_{\mathrm{H}_{2} \mathrm{O}}}
$$




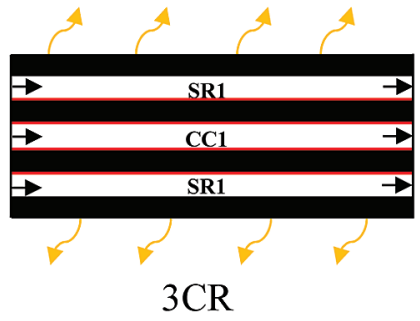

$3 \mathrm{CR}$

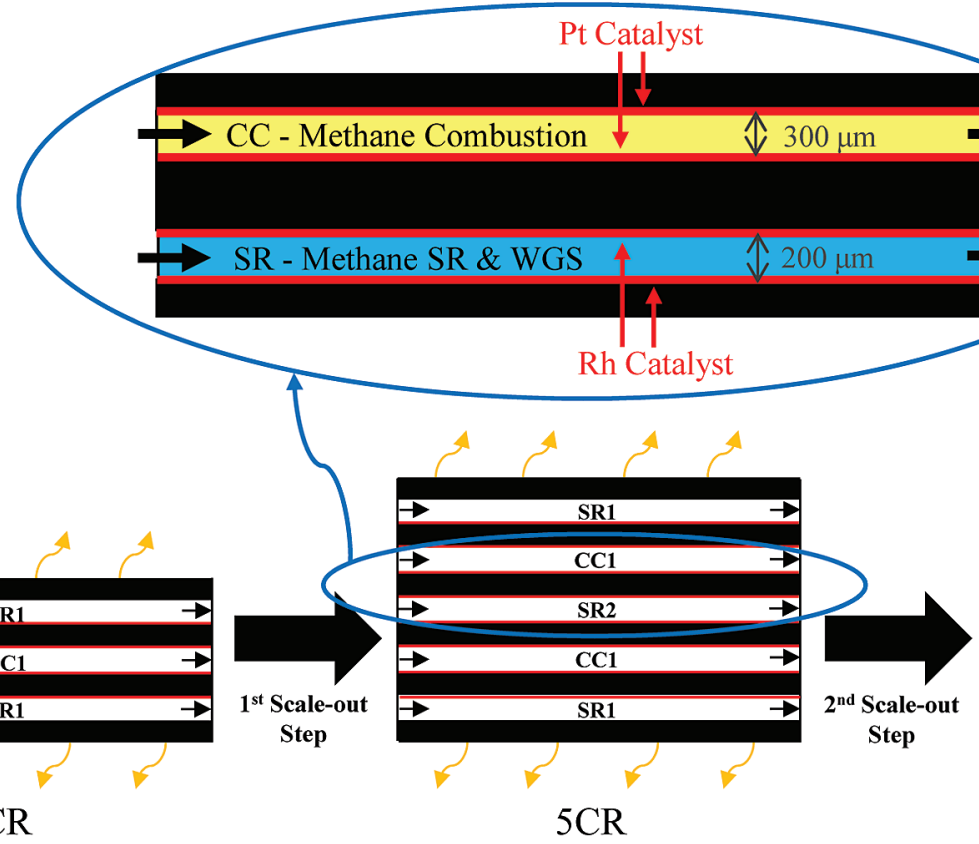

Throughput $=3 \mathrm{CR} \times 2$

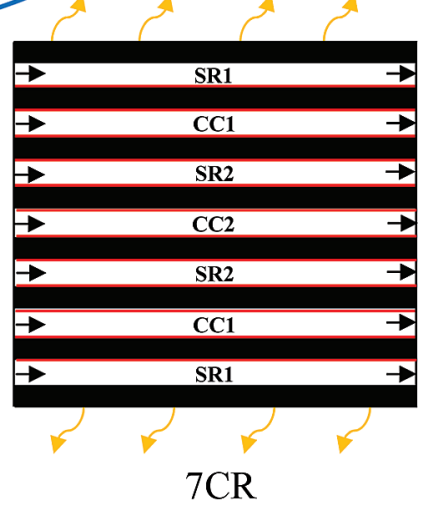

Throughput $=3 \mathrm{CR} \times 3$

Figure 2. Microreactor scale-out strategy. Gap sizes and wall thicknesses are shown in the enlarged (circled) section of the five-channel reactor (5CR). To reduce computational time, a symmetry plane is placed at the middle of the central channel. Channels are numbered such that outer channels have lower numbers and the center channel has the highest. All stacks are $5 \mathrm{~cm}$ in length. Red lines indicate catalytic surfaces.

and

$$
K_{\text {equilibrium,sr }}=\exp \left(-\frac{\Delta G_{\mathrm{SR}}^{0}(T)}{R T}\right)
$$

$\Delta G_{\mathrm{SR}}^{0}(T)$ is calculated from thermodynamic relationships using temperature-dependent heat capacities. ${ }^{32}$ The approach to equilibrium for WGS can be written as

$$
\eta_{\mathrm{wgs}}=\frac{K_{\mathrm{wgs}}}{K_{\text {equilibrium,wgs }}}
$$

Here, $K_{\text {wgs }}$ and $K_{\text {equilibrium,wgs }}$ are calculated in a similar manner as that done for $\eta_{\mathrm{sr}}$ in eqs 9 and 10.

3.2. Scale-Out Methodology. A scale-out model that keeps several reactor parameters constant is proposed, to appropriately compare stacks of different sizes. Stack flow rates and catalyst placement on different walls are fixed using information from infinite-stack and two-channel reactor (2CR) simulations, respectively (see the Supporting Information for details). Our scale-out strategy is based on two additional design principles: (I) SR channels are positioned at the stack edges, to insulate combustion channels from external heat losses, and (II) the SR heat duty per combustion channel is the same for all stack sizes. Other designs, such as placing combustion channels at the edges or using different throughputs for inner and outer channels, are also possible (and, in some instances, preferable). For example, simulations for three-channel reactor (3CR) and nine-channel reactor (9CR) indicate that the differences in stability and performance of placing the combustion channels in the exterior are usually within $10 \%-20 \%$ of the design used here; therefore, other designs are not discussed further here.

The starting point of this scale-out study is the 3CR reactor, which is comprised of a central catalytic combustion channel (CC1) encompassed by two SR channels (see Figure 2). This configuration satisfies principle (I), because the outer SR channels insulate $\mathrm{CC} 1$ from edge heat loss. Both interior surfaces of $\mathrm{CC} 1$ are catalytic (indicated by red lines in color version) and the reduced rate expression for methane combustion on $\mathrm{Pt} /$ $\mathrm{Al}_{2} \mathrm{O}_{3}$ (eq 4) is applied at these faces. The two outer SR channels have only one catalytic surface, and the kinetics for SR (eq 5) and WGS (eq 6) on $\mathrm{Rh} / \mathrm{Al}_{2} \mathrm{O}_{3}$ are implemented at the inner SR channel wall face (adjacent to CC1). Because the outer SR channel wall is closer to the stack edge, where heat losses are prevalent, temperatures are lower and no catalyst is placed there. This choice is motivated from our $2 \mathrm{CR}$ simulations, which indicate that exothermic and endothermic catalytic surfaces should be placed on opposite wall faces to maximize methane conversion and minimize hot-spot formation (see the Supporting Information).

In the first scale-out step, one combustion and one SR channel are added to the $3 \mathrm{CR}$ reactor to form a five-channel reactor (5CR). To accomplish objective (II) and keep the SR load per combustion channel constant, the inlet velocity of the inner SR channel of the 5CR (SR2) is increased by a factor of 2. This is done because SR2 consumes heat generated in combustion channels both above and below it, while the outer SR channel (SR1) can only draw heat from one combustion channel. Similarly, as we scale-out, SR1 has only one catalytic surface (at the innermost wall) while all inner channels (SR2, CC1, CC2 in Figure 2) have two.

The inlet equivalence ratio for the combustion channels is 0.92 , while the $\mathrm{H}_{2} \mathrm{O}: \mathrm{CH}_{4}$ ratio is set at 2:1 with $1 \% \mathrm{~N}_{2}$ (molar) for SR channels. The steam:methane ratio is chosen to represent the inlet composition of industrial methane steam reformers. ${ }^{25}$ Inlet velocities of 6.1 and $3.05 \mathrm{~m} / \mathrm{s}$ are used in combustion channels for high- and mid-wall thermal conductivities, respectively, based on the fact that, under adiabatic heat-transfer conditions, $>99.99 \%$ methane conversion is achieved (see the Supporting Information). These are in the range of flow velocities used in previous CFD simulations of catalytic combustion systems. ${ }^{13,31,33,34}$ For the 
Table 1. Microreactor Stack Flow Parameters for Both Inner and Outer Channels for Wall Thermal Conductivities of $k=100$ and 23 $\mathbf{W} /(\mathbf{m ~ K})$

\begin{tabular}{|c|c|c|c|c|}
\hline \multirow[b]{2}{*}{$\begin{array}{c}\text { flow } \\
\text { parameter }^{a}\end{array}$} & \multicolumn{2}{|c|}{$k=100 \mathrm{~W} /(\mathrm{m} \mathrm{K})$} & \multicolumn{2}{|c|}{$k=23 \mathrm{~W} /(\mathrm{m} \mathrm{K})$} \\
\hline & $\begin{array}{l}\text { inner } \\
\text { channels }\end{array}$ & $\begin{array}{c}\text { outer } \\
\text { channels }\end{array}$ & $\begin{array}{c}\text { inner } \\
\text { channels }\end{array}$ & $\begin{array}{c}\text { outer } \\
\text { channels }\end{array}$ \\
\hline inlet velocity $[\mathrm{m} / \mathrm{s}](\mathrm{CC})$ & 6.1 & 6.1 & 3.05 & 3.05 \\
\hline inlet velocity $[\mathrm{m} / \mathrm{s}]$ (SR) & 4.0 & 2.0 & 2.3 & 1.15 \\
\hline equivalence ratio $(\mathrm{CC})$ & 0.92 & 0.92 & 0.92 & 0.92 \\
\hline $\mathrm{H}_{2} \mathrm{O}: \mathrm{CH}_{4}$ ratio $(\mathrm{SR})$ & 2 & 2 & 2 & 2 \\
\hline
\end{tabular}

${ }^{a}$ Catalytic combustion (CC) streams are fed at $300 \mathrm{~K}$, whereas SR reactants are preheated to $400 \mathrm{~K}$.

SR channels, two sets of outer/inner channel inlet velocities are employed: $2.0 / 4.0 \mathrm{~m} / \mathrm{s}$ for the high-wall thermal conductivity case, and $1.15 / 2.3 \mathrm{~m} / \mathrm{s}$ for the moderate conductivity value, as shown in Table 1. The SR flow rates are determined from infinite stack simulations, as explained in the Supporting Information of this work. Combustion and SR gap sizes are constant in all simulations at 300 and $200 \mu \mathrm{m}$, respectively. For all stacks, the wall thicknesses are fixed at $750 \mu \mathrm{m}$ and the channels are $5 \mathrm{~cm}$ in length. With these channel gap sizes, inlet compositions, and flow rates, $\sim 40 \%$ of the methane feed is burned in the combustion channels, while the remainder is sent to the SR channels.

3.3. Performance Metrics. Several metrics can be used to compare microreactor stacks. Energy efficiency should be maximized. The construction material is also important, because it significantly affects performance (hot spots, conversion, etc.) and cost. A final metric is the stability of the stack under increasing external heat loss. All of these metrics will be addressed, but stack stability and material choice will receive special attention, because they are especially challenging for methane SR.

3.3.1. External Heat Loss. Heat losses were modeled using Newton's law of cooling:

$$
Q=h \int_{A} \Delta T \mathrm{~d} A
$$

Heat transfer from the stack to the ambient can be varied through the heat loss coefficient $(h)$ at the external walls. The integral is evaluated over the external surface of the reactor, $Q$ is the total power transferred from the walls to the ambient, and $\Delta T$ is the difference between the temperature at the reactor wall and the ambient temperature. The stability of different stacks can be compared using the critical heat-loss coefficient. As $h$ is increased at the stack edges, the system reaches a point where any further increase causes the heat loss to the ambient to be too large and combustion processes within the stack cease. Once combustion reactions stop, the stack thermally equilibrates with the ambient and no syngas is produced. For larger stacks (i.e., the fifteen-channel reactor (15CR)), we find a partially ignited mode for intermediate heat-loss coefficients, where inner combustion channels function at high conversion after the outer channels fail. Failure of the outer combustion channels reduces efficiency and throughput. This phenomenon is discussed further in section 6. To connect the stability of the different simulated stacks with laboratory microsystems, the critical heat-loss coefficient of a stack is compared to an estimate of the laboratory heat-loss coefficient. In previous work, the laboratory heat-loss coefficient was estimated to be $64.5 \mathrm{~W} /\left(\mathrm{m}^{2}\right.$ $\mathrm{K})$ using a $2 \mathrm{D}$ pseudo-homogeneous model with the kinetics used herein. ${ }^{31}$ This value lumps convective and radiant phenomena and includes the effects of laboratory equipment (insulation, nuts, bolts, piping, etc.). The laboratory heat- loss coefficient was also independently estimated by simulating an experimental microreactor (at various heat-loss coefficients) at full conversion from an overall energy balance and then comparing the model results to experimental data. A value of $60 \pm 20 \mathrm{~W} /\left(\mathrm{m}^{2} \mathrm{~K}\right)$ was found. Given these estimates, the laboratory heat-loss coefficient is taken to be $60 \mathrm{~W} /\left(\mathrm{m}^{2} \mathrm{~K}\right)$.

3.3.2. Stack Construction Materials. Two wall thermal conductivities are modeled. A moderate conductivity value of $23 \mathrm{~W} /(\mathrm{m} \mathrm{K})$ is chosen that is similar to the value for stainless steel. A second, higher value of $100 \mathrm{~W} /(\mathrm{m} \mathrm{K})$ is employed that is near reported values for highly conductive materials such as silicon carbide, low-alloy steels, and copper alloys. ${ }^{35}$ Silicon carbide has high chemical and mechanical stability at high temperatures, but it is 1-2 orders of magnitude more expensive than stainless steel. ${ }^{36}$ Low alloy steels and copper alloys are inexpensive but have reduced thermal stability, compared to stainless steel. ${ }^{35}$ In this work, we ignore such downsides to explore the effect of wall thermal conductivity on performance.

3.3.3. Energy Efficiency. The efficiency of the stacks is calculated based on the methane input and syngas product. The energy content of the methane feed is calculated based on the heat of combustion at $300 \mathrm{~K}(-803 \mathrm{~kJ} / \mathrm{mol})$. Similarly, the power produced in the form of syngas is determined from the lower heating value (LHV) of hydrogen $\left(\mathrm{H}_{2}\right)$ and carbon monoxide $(\mathrm{CO})(-241$ and $-283 \mathrm{~kJ} / \mathrm{mol}$, respectively). The efficiency $(\eta)$ can be calculated from the following equation:

$$
\eta=\frac{F_{\mathrm{CO}, \text { out }} \mathrm{LHV}_{\mathrm{CO}}+F_{\mathrm{H}_{2} \text {,out }} \mathrm{LHV}_{\mathrm{H}_{2}}}{F_{\mathrm{Me}, \text { in }} \mathrm{LHV}}
$$

In eq $13, F_{i}$ represents the total molar flow rate of species $i$ into or out of the stack.

\section{Evaluation of the Three-Channel Reactor (3CR)}

First, the behavior of the base-unit stack, the 3CR, is studied as a function of edge heat loss. Figure 3 indicates that the efficiency (Figure 3a) and maximum wall temperature (Figure $3 b)$ decrease linearly as the heat-loss coefficient increases, whereas the ambient power loss (Figure 3a) increases linearly as the heat-loss coefficient increases. In contrast, methane conversion within the combustion channel is a nonlinear function of the heat-loss coefficient (Figure 3c). Interestingly, methane conversion in this channel is $>95 \%$, even at the critical heatloss coefficient. On the other hand, the methane conversion in SR channels decreases significantly as the heat loss increases (see Figure 3c).

The critical heat-transfer coefficient of the $3 \mathrm{CR}$ is only 17.5 $\mathrm{W} /\left(\mathrm{m}^{2} \mathrm{~K}\right.$ ) (indicated by the vertical arrow in Figure $3 \mathrm{c}$ ), which is much less than the laboratory estimate of $60 \mathrm{~W} /\left(\mathrm{m}^{2} \mathrm{~K}\right)$. This indicates that the $3 \mathrm{CR}$ cannot function in the laboratory. One reason for the low critical heat-transfer coefficient value is that the external surface area:volume ratio $(A / V)$ of the $3 \mathrm{CR}$ is higher $\left(580 \mathrm{~m}^{-1}\right)$ than that used in industrial steam reformers $(40$ $\left.\mathrm{m}^{-1}\right){ }^{25}$ High $A / V$ values within microreactors is often beneficial, because it allows for faster heat and mass transfer within and between channels. However, as is seen in the case of the $3 \mathrm{CR}$, external heat loss to the ambient also is increased. Also, methane-powered microreactors are less stable than microcombustors that are powered with larger hydrocarbons, because methane has a higher energy barrier for adsorption on $\mathrm{Pt} /$ $\mathrm{Al}_{2} \mathrm{O}_{3}{ }^{30}$

To better understand energy utilization in the 3CR, the destination of inlet methane combustion energy is indicated in 

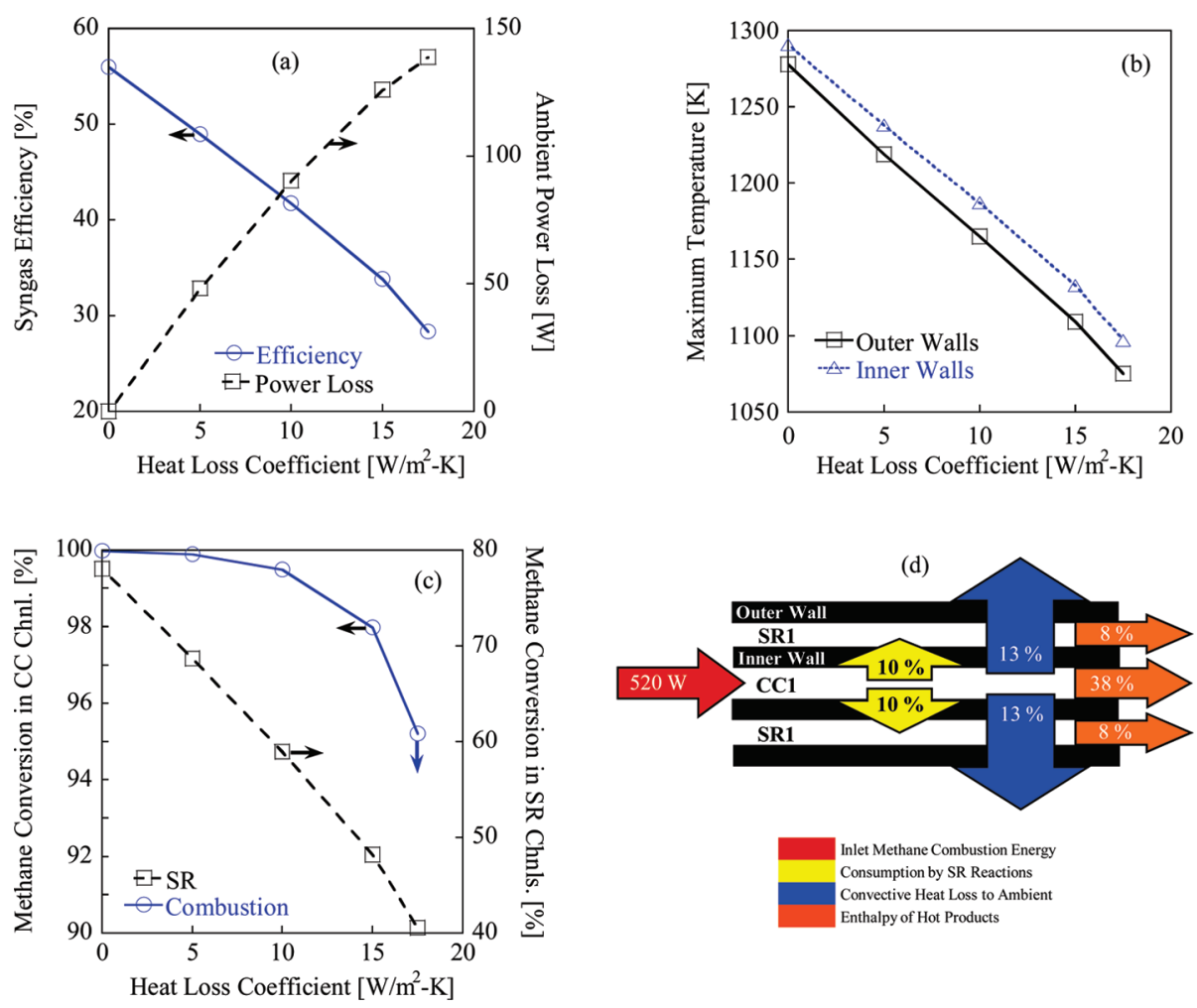

Figure 3. Performance of the base-unit three-channel reactor (3CR), in terms of (a) efficiency (circles) and power loss to ambient (squares), (b) maximum wall temperature, and (c) methane conversion in combustion and SR channels. In addition, the energy flow for the 3CR at the critical heat-loss coefficient $\left(17.5 \mathrm{~W} /\left(\mathrm{m}^{2} \mathrm{~K}\right)\right)$ is shown in panel $(\mathrm{d})$. The (blue) vertical arrow in panel (c) indicates the critical heat-loss coefficient for the 3CR. All data are for a wall thermal conductivity of $100 \mathrm{~W} /(\mathrm{m} \mathrm{K})$. Power calculations (panels (a) and (d)) are based on a 10-cm-wide stack.

Figure $3 \mathrm{~d}$. At the critical heat-transfer coefficient for the $3 \mathrm{CR}$ $\left(17.5 \mathrm{~W} /\left(\mathrm{m}^{2} \mathrm{~K}\right)\right)$, approximately half of the inlet chemical energy is lost in the form of hot products. An additional quarter is transferred from the stack walls to the ambient. Therefore, only $20 \%$ of the inlet combustion energy is utilized in SR reactions to produce syngas. These values can be compared to those of an (adiabatic) infinite stack, where $29 \%$ of the inlet energy is utilized in SR reactions and the remainder leaves via hot products (see the Supporting Information).

With this understanding of performance and stability of the base-unit stack, the edge and material effects are studied next as the 3CR is scaled-out to larger stacks.

\section{Scale-Out Effects}

Using the aforementioned scale-out strategy, different stacks with high- or mid-wall thermal conductivity are studied as a function of the heat-loss coefficient. Energy efficiency is a common metric used to study microreactor stacks and power generation systems in general. Figure 4a shows that the efficiency of stacks for high-wall thermal conductivity stacks $(k=100 \mathrm{~W} /(\mathrm{m} \mathrm{K}))$ is approximately linear, with respect to the heat-loss coefficient, with the end points of each curve representing the critical heat-loss coefficient. Because of decreased $A / V$ values, syngas efficiency increases with increasing stack size, as larger stacks lose a lesser fraction of inlet energy to the ambient (Figure 4b). In addition to ambient heat loss, a large fraction of the stack energy input is retained in hot products $(\sim 60 \%)$, leaving a lesser amount to fuel endothermic $\mathrm{SR}$ reactions. At the small scales studied here, the efficiency increases substantially with increasing stack size but is considerably lower than that of large stacks under typical laboratory heat loss. Larger stack sizes are not investigated here; however, it is likely that efficiencies of these systems are near the infinite stack value (denoted by the dashed line in Figure $4 \mathrm{a}$ ).

For the particular conditions studied here, maximum wall temperatures are reasonable for all stack sizes and heat-loss coefficients (see Figure 4d). Maximum temperatures occur at the lower catalytic wall of the inner combustion channel (nearest to the center of the stack). The inner combustion temperature of the basic unit (3CR) clearly is very sensitive to heat loss, whereas larger sizes (5CR and up) are less sensitive.

Stability as a function of stack size is compared for various stack sizes, in terms of the critical heat-loss coefficient. Figure $4 \mathrm{c}$ shows that stability improves with stack size. This trend is partially due to reduced external surface area per volume ratio as stack size is increased, as discussed in the previous section for the 3CR. Stacks constructed from materials with mid-wall thermal conductivities (e.g., SS) are less stable than those built from high-conductivity materials (e.g., SiC) for these conditions, although the difference is less dramatic for larger stacks. In addition, the high-wall thermal conductivity data in Figure 4c indicate that stability is not simply a linear function of $A / V$. Small stacks constructed from materials with a moderate thermal conductivity are not stable under laboratory heat-loss conditions.

\section{Stack Failure Analysis}

6.1. Stability of Smaller Stacks. To understand how smaller stacks fail, individual channels of the 9CR are examined. The effect of edge heat loss on the exit temperatures (Figure 5) and methane conversion (Figures $6 \mathrm{a}$ and $6 \mathrm{~b}$ ) is determined. Figure 5 illustrates that transverse thermal gradients develop as the edge heat loss is increased. At the critical heat-transfer coefficient of the $9 \mathrm{CR}\left(90 \mathrm{~W} /\left(\mathrm{m}^{2} \mathrm{~K}\right)\right)$, a difference in exit temperature of $\sim 350$ $\mathrm{K}$ is observed between the middle channel (SR3) and the 

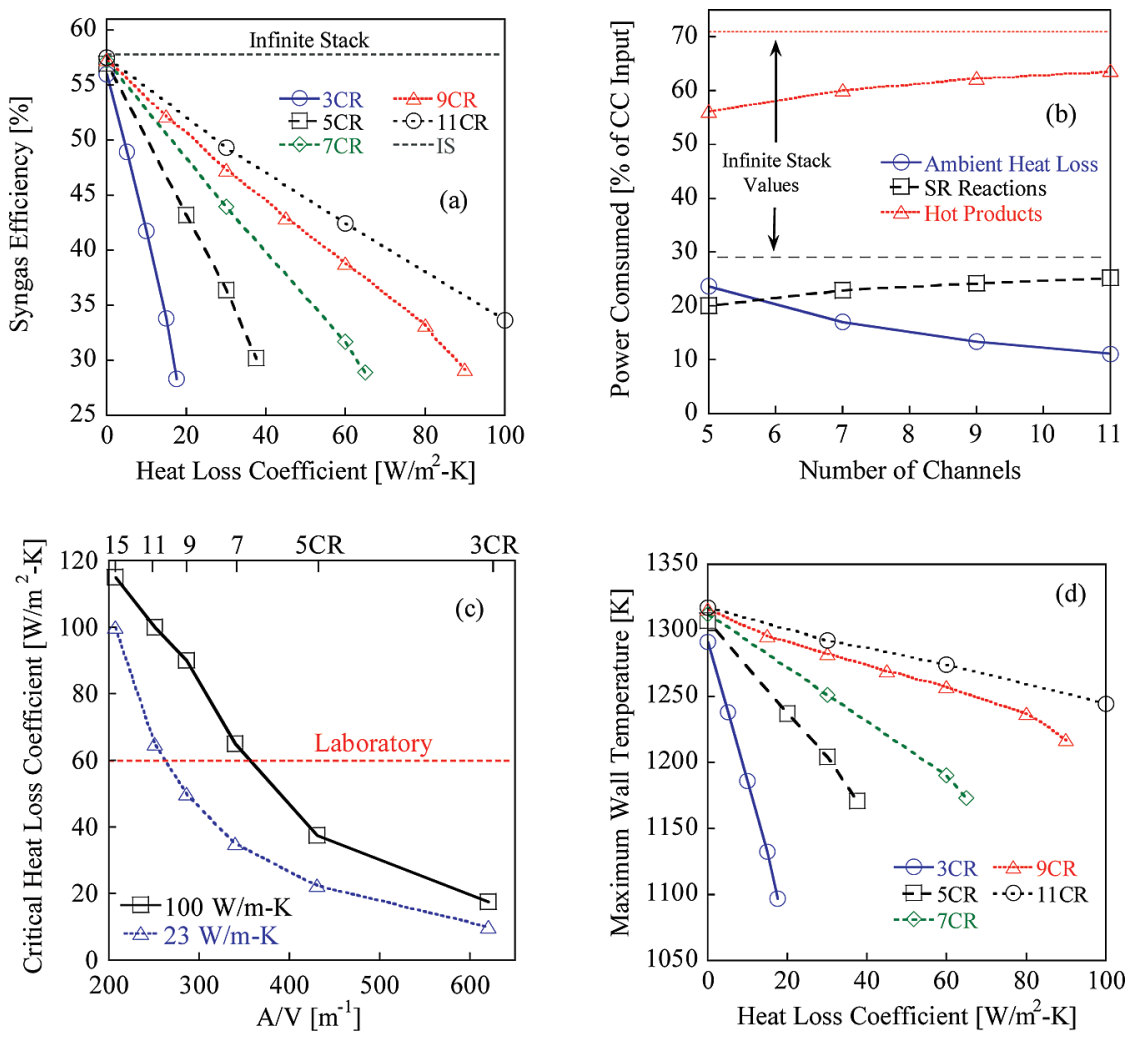

Figure 4. Stack performance in scale-out in terms of (a) efficiency, as a function of heat-loss coefficient; (b) energy consumption pathways, as a function of size (at $h=30 \mathrm{~W} /\left(\mathrm{m}^{2} \mathrm{~K}\right)$ ); (c) stability versus $A / V$; and (d) maximum wall temperature versus heat-loss coefficient. The dashed (red) line in panel (c) indicates a typical laboratory heat-loss coefficient for microreactors. A wall thermal conductivity of $100 \mathrm{~W} /(\mathrm{m} \mathrm{K})$ was used in panels (a), (b), and (d). In panel (b), energy consumption pathways for the infinite stack reactor are indicated with horizontal lines for SR reactions (dashed line) and hot products (dotted line).

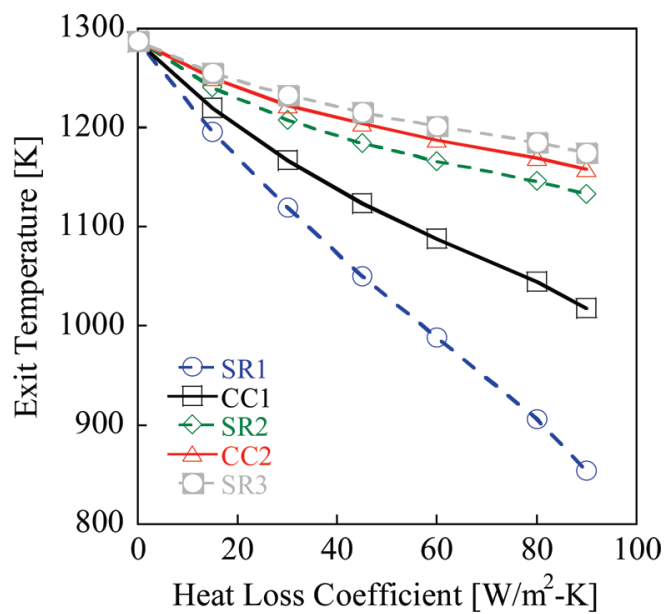

Figure 5. Thermal effects from edge heat loss on a nine channel reactor (9CR). Exit temperatures are shown as a function of heat-loss coefficient. The wall thermal conductivity is $100 \mathrm{~W} /(\mathrm{m} \mathrm{K})$.

outermost channel (SR1). At the vertical midline of the 9CR (line at $2.5 \mathrm{~cm}$ ), transverse thermal gradients are slightly larger $(\sim 450 \mathrm{~K})$ as heat generation in interior combustion channel (CC2) occurs closer to this point. These gradients are substantial, given that these channels are separated by only $4 \mathrm{~mm}$. Under laboratory heat-loss conditions $\left(h=60 \mathrm{~W} /\left(\mathrm{m}^{2} \mathrm{~K}\right)\right)$, the temperature difference between pairs of adjacent combustion and SR channels in the $9 \mathrm{CR}$ ranges from $15 \mathrm{~K}$ (interior pairs, $\mathrm{SR} 3 / \mathrm{CC} 2$ ) to $100 \mathrm{~K}$ (outer pairs, SR1/CC1). These differences are caused by edge heat losses and are larger than those predicted in infinite stack simulations, where the temperature differences between adjacent SR and combustion channels do not exceed $5 \mathrm{~K}$ (after entrance effects have subsided).

The large temperature gradients observed within the stack at high heat loss cause methane conversion in outer and inner channels to be unequal. Figure 6a shows that the conversion for inner SR channels (SR2 and SR3) is a weak function of the heat-loss coefficient. Similarly, conversion in the inner combustion channel (CC2) is $>98 \%$, even at the critical heatloss coefficient (Figure 6b). In addition, Figure 6a shows that the conversion in SR1 drops from 80\% under adiabatic conditions to $10 \%$ at the critical heat loss coefficient. Similarly, methane conversion in CC1 decreases from $>99 \%$ at low heat-loss coefficients to $84 \%$ at the critical heat-loss coefficient. Figure $6 \mathrm{~b}$ implies that $\mathrm{CC} 1$ fails first and, because of thermal coupling, ultimately causes combustion within $\mathrm{CC} 2$ to cease as well. Figure 7 expands on this conclusion and suggests that the conversion in $\mathrm{CC} 1$ is always less than that in $\mathrm{CC} 2$.

An additional effect of edge heat loss is that top and bottom catalytic walls within a single channel are not utilized equally. Figure $6 \mathrm{c}$ shows that top catalytic walls process less methane, relative to bottom walls in both SR and combustion channels. In the outer combustion channel (CC1), the top catalytic surface (nearest edge heat loss) is much less utilized than the bottom surface. Reduced activity is a product of lower temperatures at the top surface $\left(T_{\max }=900 \mathrm{~K}\right)$, relative to the bottom catalytic wall $\left(T_{\max } \approx 1150 \mathrm{~K}\right)$. Edge heat loss also causes the catalytic surfaces of inner combustion channels (CC2) to be unequally utilized, despite this channel having $>98 \%$ methane conversion at critical heat loss. As is the case with $\mathrm{CC} 1$, asymmetric activity of $\mathrm{CC} 2$ catalytic walls is due to different temperatures between top $\left(T_{\max } \approx 1150 \mathrm{~K}\right)$ and bottom $\left(T_{\max } \approx 1200 \mathrm{~K}\right)$ surfaces. 

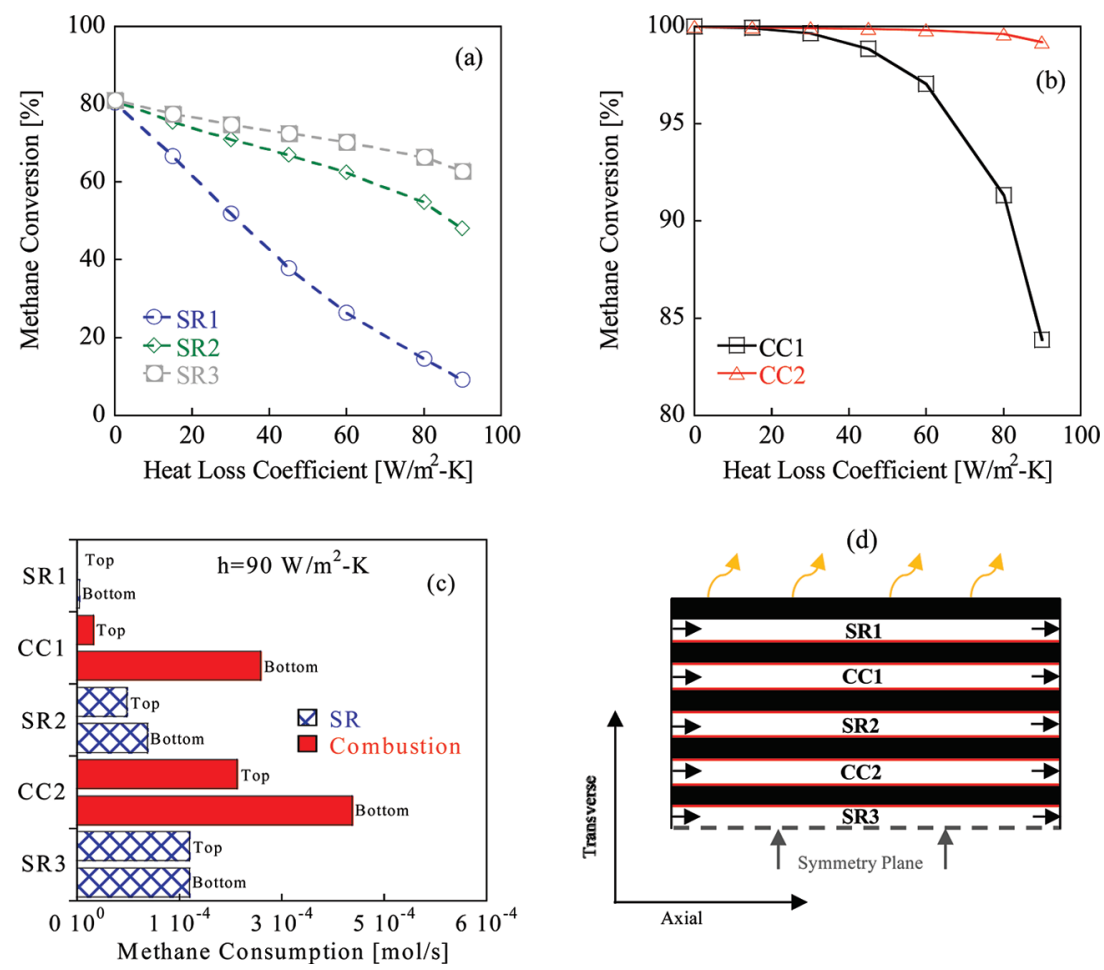

Figure 6. Effect of edge heat loss on conversion and catalyst surface utilization of a nine-channel reactor (9CR): exit methane conversion for (a) combustion and (b) SR channels, shown as a function of the heat-loss coefficient; (c) utilization of catalytic surfaces for SR and combustion channels at critical heat loss $\left(h=90 \mathrm{~W} /\left(\mathrm{m}^{2} \mathrm{~K}\right)\right)$; and (d) schematic of the $9 \mathrm{CR}$. A wall thermal conductivity of $100 \mathrm{~W} /(\mathrm{m} \mathrm{K})$ is used.

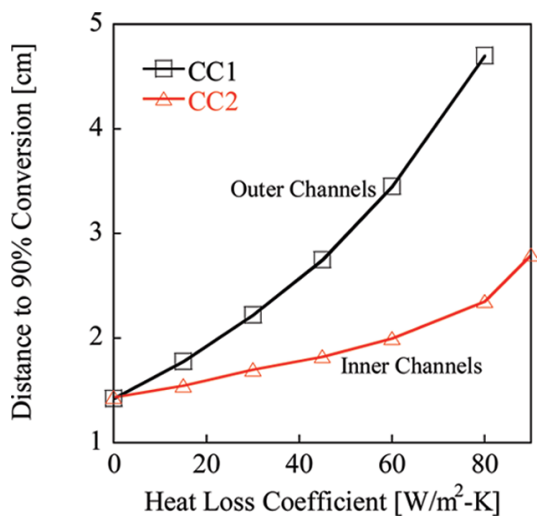

Figure 7. Reaction zone location within combustion channels of the ninechannel reactor (9CR). Distance to $90 \%$ methane conversion is shown as a function of heat-loss coefficient. Average (cup-mixing) conversion values are reported for outer (CC1) and inner (CC2) combustion channels. The wall thermal conductivity is $100 \mathrm{~W} /(\mathrm{m} \mathrm{K})$.

Unused catalytic surfaces can reduce conversion and throughput. From Figure 6c, one may conclude that edge heat loss can have undesired impact on catalyst utilization, an effect that penetrates to interior channels, even when these channels are operating with high conversion.

The location of $90 \%$ methane conversion is used to identify the reaction zone within the combustion channels of the 9CR (Figure 7). As the heat-loss coefficient increases, the reaction zone within $\mathrm{CC} 1$ moves down the reactor length while the reaction zone in CC2 is less affected by the increase in external heat loss. This indicates that at high heat loss, the $\mathrm{CC} 1$ reaction zone is further from the channel inlet and that $\mathrm{CC} 1$ causes failure.

Failure of the outer combustion channel (CC1) does not generally imply failure of the entire stack; i.e., interior combustion channel(s) (CC2) may still function even when the chemistry in CC1 dies out (as is the case with the 15CR, discussed later in this section). However, if combustion channels within stacks possess sufficient thermal coupling, failure of one channel causes all channels to fail (as is the case for the 9CR, which we consider here). To illustrate the degree of thermal coupling between combustion channels, the energy flow within the 9CR is presented for three heat-loss coefficients (see Figure 8). Heat fluxes into and out of $\mathrm{CC} 1$ and $\mathrm{CC} 2$ (each receives $520 \mathrm{~W}$ as the input combustion energy for a 10 -cm-wide stack) are shown in Figure 8. Combustion channels are separated by one SR channel (SR2). Figure 8 shows that, for adiabatic conditions, the heat flux from both $\mathrm{CC} 1$ and $\mathrm{CC} 2$ to SR2 (to perform SR reactions) are approximately equal. However, as edge heat loss increases, CC1 loses a substantial fraction of its inlet power to edge heat loss, causing a reduction of the heat flux from CC1 to SR2. This results in increased heat transfer from CC2 to SR2, because of the increase in the transverse temperature gradient. At critical heat loss $\left(90 \mathrm{~W} /\left(\mathrm{m}^{2} \mathrm{~K}\right)\right)$, the outer combustion channel (CC1) contributes only a small fraction of the power required to heat reactants and fuel SR reactions in SR2 $\left(5 \mathrm{~W}\right.$ at $h=90 \mathrm{~W} /\left(\mathrm{m}^{2} \mathrm{~K}\right)$ vs $128 \mathrm{~W}$ at $h=0$ $\left.\mathrm{W} /\left(\mathrm{m}^{2} \mathrm{~K}\right)\right)$. This causes a $40 \%$ reduction in methane conversion in SR2, compared to the adiabatic case (see Figure 6a), as the increase in power transfer from $\mathrm{CC} 2$ is unable to make up for the reduced contribution from $\mathrm{CC} 1$ ( $\mathrm{CC} 1$ decrease, $123 \mathrm{~W}$; $\mathrm{CC} 2$ increase, $50 \mathrm{~W}$ ).

Next, the mechanism for stability loss in the outer combustion channel (CC1) is investigated. There are two mechanisms for loss of stability. In combustion systems plagued by blowout, the reaction zone migrates down the reactor length until it eventually leaves the reactor and combustion ceases. Reactor temperatures are typically high and residence time is crucial. On the other hand, extinction temperatures are generally low and the reaction zone is delocalized, reducing the overall reaction rate. Both failure mechanisms have been documented in gas- 

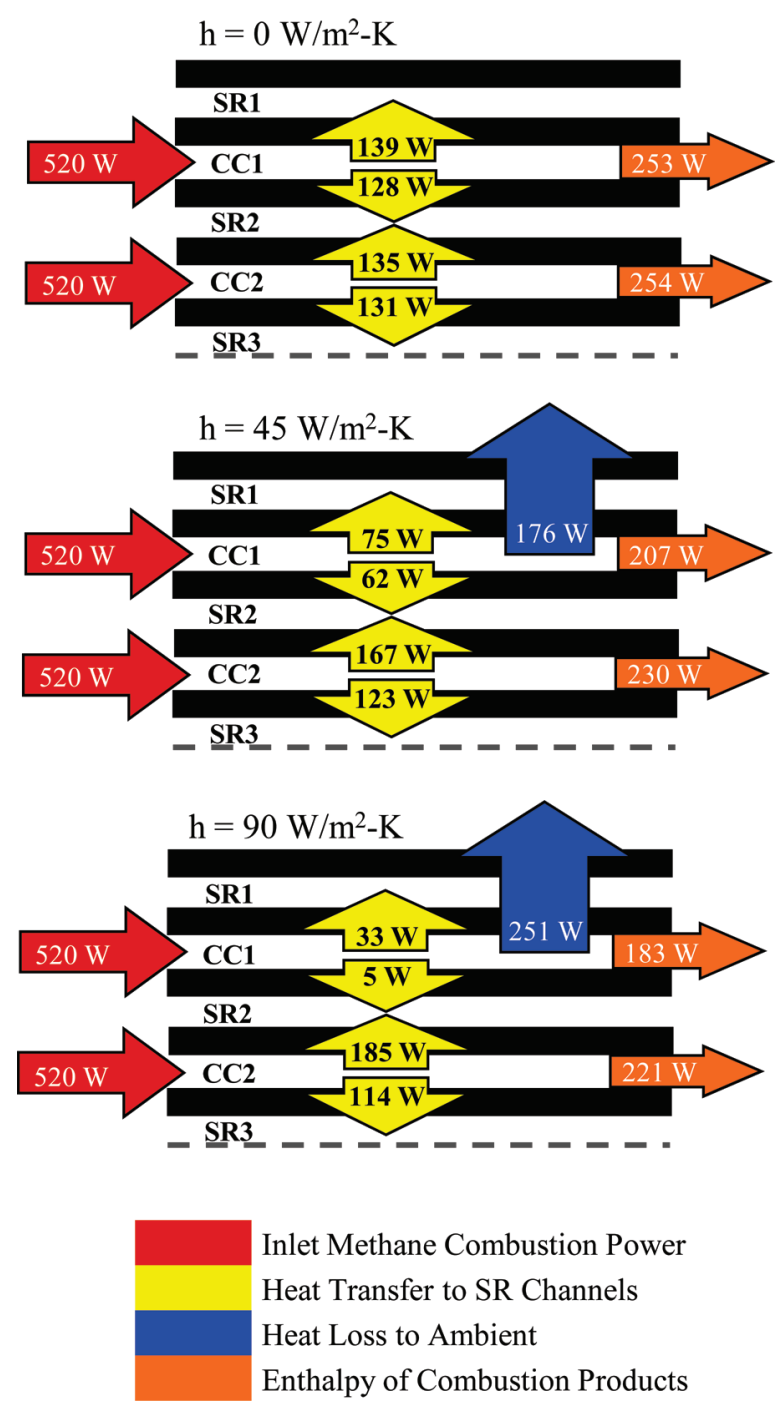

Figure 8. Energy flow diagrams for adiabatic, moderate $\left(h=45 \mathrm{~W} /\left(\mathrm{m}^{2}\right.\right.$ $\mathrm{K})$ ), and critical $\left(h=90\left(\mathrm{~W} /\left(\mathrm{m}^{2} \mathrm{~K}\right)\right)\right.$ heat loss for the $9 \mathrm{CR}$. Uncombusted methane is not taken into account in the enthalpy of combustion products (orange arrows). Dashed (gray) lines indicate symmetry planes. The wall thermal conductivity is $100 \mathrm{~W} /(\mathrm{m} \mathrm{K})$, and power values are for a stack width of $10 \mathrm{~cm}$.

phase microburners. ${ }^{37-39}$ Previous work on propane catalytic combustion microreactors lacked a clear demarcation between extinction and blowout, because low activation energies lead to delocalized reaction zones. ${ }^{31}$ Microreactor stacks studied here are powered by methane rather than propane; therefore, the combustion is slower, because of the high activation energy for fuel adsorption. The higher adsorption barrier causes more localized reaction zones near failure, which allows for a clearer demarcation between blowout and extinction in our stacks. At the same time, the thermal coupling between multiple channels of stacks makes analysis more difficult.

Figure 9a shows the maximum temperature for the top and bottom catalytic walls of the outer combustion channel (CC1), as a function of size at the critical heat loss coefficient of each stack, whereas Figure $9 \mathrm{~b}$ illustrates the location of maximum temperature, relative to the entrance of CC1. Figure 9a indicates that top walls (near stack edge) are cooler than bottom walls (away from stack edge) and top walls of high conductivity stacks are cooler than top walls of moderate conductivity stacks. This implies that top walls play a less significant role at critical heat loss for high conductivity stacks (similar to what the data in Figure 6c suggest).

The maximum temperature location for stacks operating at the critical heat-loss coefficient (different for each stack) is shown as a function of stack size in Figure $9 \mathrm{~b}$. The maximum temperature provides an indicator of the reaction zone within CC1. For adiabatic stacks with high and moderately conductive walls, the maximum temperature location is 1.4 and $1.0 \mathrm{~cm}$ from the inlet, respectively. The maximum temperature location moves away from the inlet in larger stacks, indicating reaction zone migration. This suggests that blowout could be a factor in the failure of larger stacks as the reaction zone nears the exit of the outer combustion channel.

Figure 10 further illustrates the reaction zone location in CC1 by depicting the axial location of $10 \%$ (left hashes) and $90 \%$ (right hashes) methane conversion at the critical heat-loss coefficient (a different value for each stack). The reaction zone is larger for highly conductive walls, compared to stacks with moderately conductive walls, because of higher peak temperatures in the second case that increase the average reaction rate. The reaction zone for larger stacks is near the outlet of $\mathrm{CC} 1$ at the critical heat-loss coefficient. This is due to reaction zone migration (a signature of blowout) in CC1. For small stacks (3CR and 5CR), the reaction zone is far from the $\mathrm{CC} 1$ exit, indicating that stability is lost via extinction. Figure 10 supports the hypothesis that larger stacks are controlled via blowout, whereas failure in smaller stacks is due to extinction.

To test the hypothesis that outer channels in larger stacks fail because of blowout, the flow in outer combustion channels (CC1) of the 9CR was increased. An increase in flow rate increases the energy input to the stack; moreover, if the additional methane input is combusted, stack temperatures are elevated and, ultimately, the critical heat-loss coefficient is increased. In contrast, if a channel is controlled from blowout, the increased flow will not result in increased energy generation, because the residence time is insufficient to burn the additional fuel. To benchmark increases in the critical heat-loss coefficient when flow is increased to the outer combustion channel, the effect of increased flow to the inner channels on critical $h$ is used for comparison. A $25 \%$ increase in flow to the inner combustion channel (CC2) results in a 33\% increase in critical heat-loss coefficient. The same flow increase to the outer combustion channel (CC1) does not change the critical $h$ value, because little of the additional methane input combusts and stack temperatures are not increased. These simulations indicate that the outer combustion channel fails because of blowout.

6.2. Stability of Larger Stacks. While the stability of smaller stacks ( $<15$ channels) is bimodal (combustion channels are either all ignited or all extinguished), the 15CR exhibits more-complex operation. Figure 11 shows conversion and outlet temperatures of the individual channels of the $15 \mathrm{CR}$ for a wall thermal conductivity of $100 \mathrm{~W} /(\mathrm{m} \mathrm{K})$. For low heat-loss coefficients ( $h$ $\left.\leq 115 \mathrm{~W} /\left(\mathrm{m}^{2} \mathrm{~K}\right)\right)$, all combustion channels are ignited and operate at high temperature and conversion. At intermediate heat-loss coefficients $\left(115 \mathrm{~W} /\left(\mathrm{m}^{2} \mathrm{~K}\right)<h \leq 130 \mathrm{~W} /\left(\mathrm{m}^{2} \mathrm{~K}\right)\right)$, conversion is low $(<10 \%)$ in outer combustion channels and high $(\geq 80 \%)$ for inner combustion channels. In this parameter range, heat from the interior of the stack is able to compensate for reduced heat generation due to the failure of the outer combustion channel (CC1). This behavior is different from smaller stacks, where combustion channels are more strongly thermally coupled and cannot function independent of each other. Finally, for high heat-loss coefficients $\left(h>130 \mathrm{~W} /\left(\mathrm{m}^{2}\right.\right.$ $\mathrm{K})$ ), both inner and outer combustion channels are extinguished 

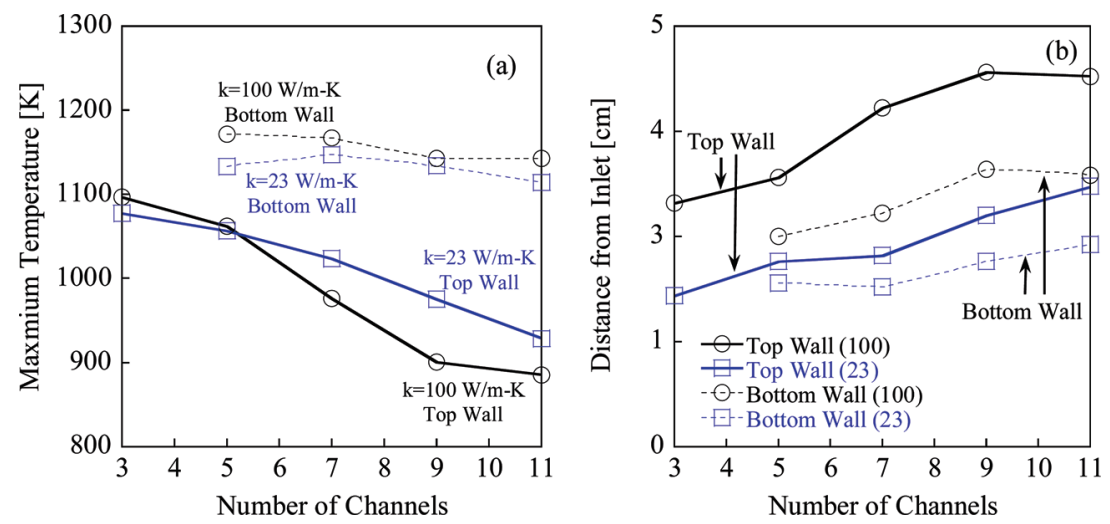

Figure 9. Reaction zone in the outer combustion channel (at critical heat loss) as a function of stack size ((a) the maximum wall temperature and (b) the maximum wall temperature location for top and bottom walls of stacks is shown during scale-out). The three-channel reactor (3CR) has only a top wall and, therefore, no bottom wall data are shown for this stack.

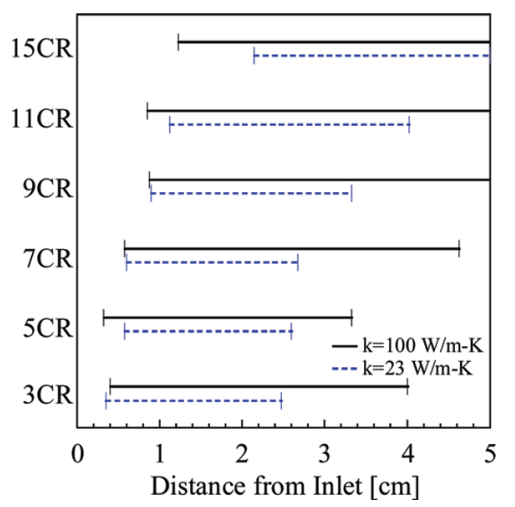

Figure 10. Reaction zone location in outer combustion channel (CC1) at the critical heat-loss coefficient (different for each stack). Horizontal lines represent the location of the reaction zone with the distance to $10 \%$ methane conversion being the start (left vertical bars) and the distance to $90 \%$ methane conversion being the end (right vertical bars). Data are taken for five stack sizes with both high-wall (solid black lines) and mid-wall (dashed blue lines) thermal conductivities.

and complete stack failure occurs. Therefore, the $15 \mathrm{CR}$ represents a size where stacks transition from typical bimodal behavior (all ignited or all extinguished channels) to bimodal operation with all combustion channels being fully ignited or the outer one only being extinguished for the operating conditions studied here. For larger stack sizes (more than 15 channels) or different operating conditions, more operational modes are possible. Such complex behavior obviously cannot be captured with a simple linear scale-out model.

\section{Comparison to Conventional Technology}

Valuable perspective can be gained by comparing the performance of microreactor stacks to conventional methane steam reformers. In this work, several indices are used to benchmark characteristics of microreactor stacks: volume index (VI), efficiency index (EI), catalyst weight index (CWI), and catalyst cost index (CCI). VI and CWI were used by Zanfir and Gavriilidis to evaluate parallel-plate steam reformers operating with nickel catalysts, but their comparison was based on methane throughput, ${ }^{12}$ whereas here, we have reset the basis to be hydrogen output. Hydrogen production rates are taken from previously published plant data for the conventional case, ${ }^{40}$ whereas microtechnology throughputs are determined in this work. In addition, inlet conditions between microreactor stacks and conventional systems are different, and the effect of this is determined in the Supporting Information of this work.
7.1. Definition of Performance Indices. The volume index (VI) is defined as the ratio of microreactor and conventional specific powers or throughputs:

$$
\mathrm{VI}=\frac{\left(Q_{\mathrm{H}_{2}} V^{-1}\right)_{\mu}}{\left(Q_{\mathrm{H}_{2}} V^{-1}\right)_{\mathrm{c}}}
$$

Here, the subscripts $\mu$ and $\mathrm{c}$ indicate micro and conventional systems. $V$ is the volume of stacks, and $Q_{\mathrm{H}_{2}}$ is the hydrogen power output (in terms of hydrogen combustion energy at 300 $\mathrm{K})$. The volume of the conventional system is calculated from the literature, ${ }^{40}$ whereas microchannel stack volumes are determined from the scale-out model introduced in this work.

The efficiency index (EI) compares the energy efficiency of the stacks to that of conventional technology:

$$
\mathrm{EI}=\frac{\eta_{\mu}}{\eta_{\mathrm{c}}}
$$

Here, efficiency $(\eta)$ is calculated similar to that described in eq 13 , with the only difference being that $\eta_{\mathrm{c}}$ includes hydrogen input to the plant furnace. It is important to note that heat recuperation has not been taken into account in the calculation of $\eta_{\mathrm{c}}$ or $\eta_{\mu}$.

The catalyst weight index (CWI) compares hydrogen power output per unit supported catalyst weight $\left(M_{\text {cat }}\right)$ of micro and conventional systems:

$$
\text { CWI }=\frac{\left(Q_{\mathrm{H}_{2}} M_{\text {cat }}{ }^{-1}\right)_{\mu}}{\left(Q_{\mathrm{H}_{2}} M_{\mathrm{cat}}{ }^{-1}\right)_{\mathrm{c}}}
$$

To calculate $M_{\text {cat }}$ (sum of support and metal masses) for stacks, the properties of the supported platinum and rhodium catalysts are specified (see Table 2). Parameters used in this calculation are comparable to catalysts used in experimental catalytic microcombustors. ${ }^{33,41}$

Finally, the catalyst cost index (CCI) is defined as the ratio of hydrogen power output per unit catalyst metal cost $\left(C_{\text {cat }}\right)$ and provides an economic comparison of the two processes.

$$
\mathrm{CCI}=\frac{\left(Q_{\mathrm{H}_{2}} C_{\mathrm{cat}}^{-1}\right)_{\mu}}{\left(Q_{\mathrm{H}_{2}} C_{\mathrm{cat}}^{-1}\right)_{\mathrm{c}}}
$$

Details for calculating $C_{\mathrm{cat}}$ are given in the Supporting Information. 

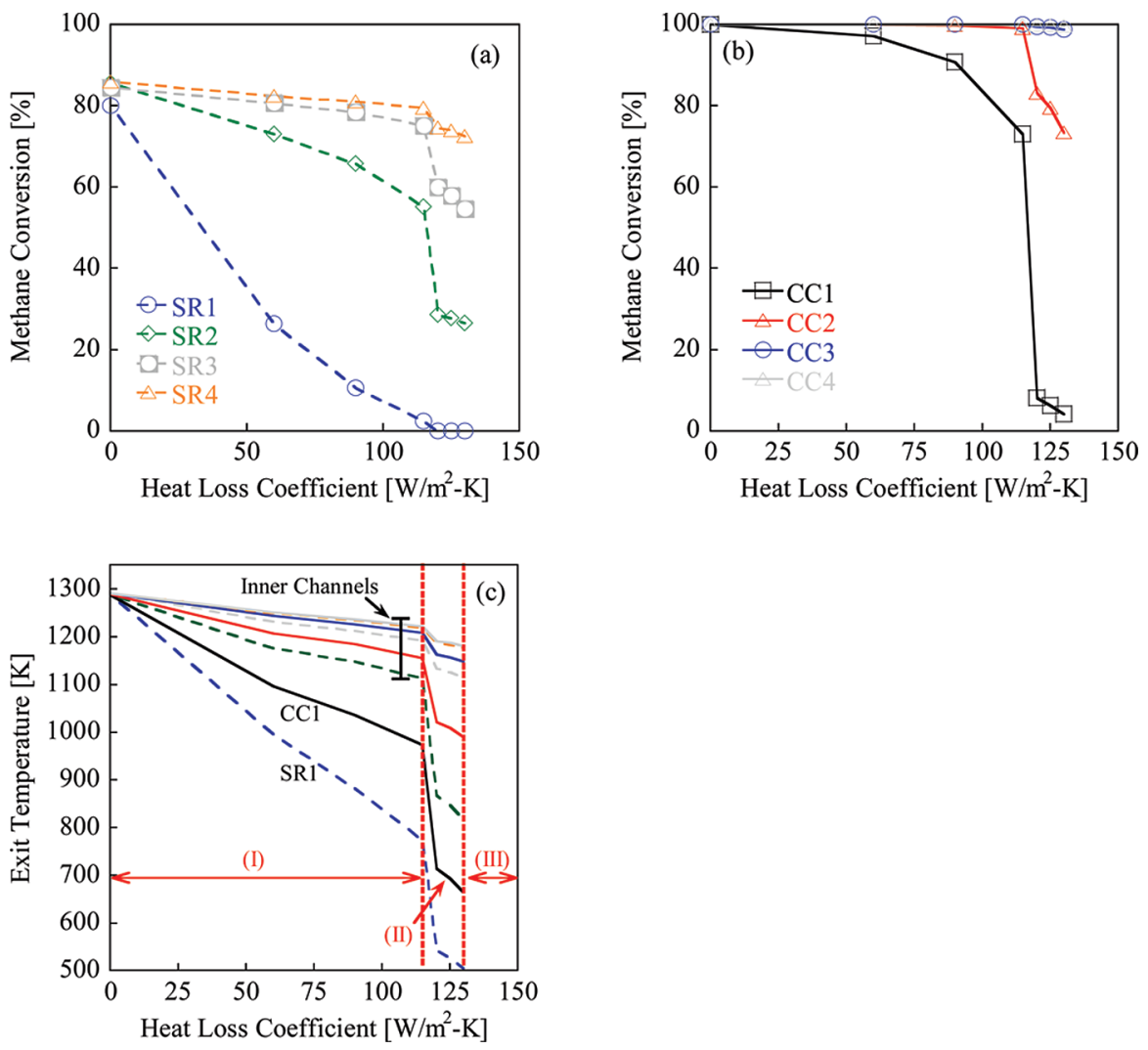

Figure 11. (a and b) Conversion and (c) exit temperature for 15CR channels, as a function of the heat-loss coefficient. In panel (c), three operating modes are illustrated: (I) all combustion channels ignited, (II) inner channels functioning while outer ones are not, and (III) no combustion in any of the combustion channels. Data are for a wall thermal conductivity of $100 \mathrm{~W} /(\mathrm{m} \mathrm{K})$.

Table 2. Input Parameters for the Three Cases Presented To Determine Variability in Performance Indices (PI)

\begin{tabular}{|c|c|c|c|c|}
\hline $\begin{array}{l}\text { input parameters } \\
\text { (affected indices) }\end{array}$ & case A (nominal) & case B (improved) & case $\mathrm{C}$ (worst) & comments \\
\hline $\begin{array}{l}\text { Throughput } \\
\text { inlet velocity (VI, EI, } \\
\text { CWI, CCI) }\end{array}$ & $6.1 \mathrm{~m} / \mathrm{s}(\mathrm{CC}), 4.0 \mathrm{~m} / \mathrm{s}(\mathrm{SR})$ & $9.15 \mathrm{~m} / \mathrm{s}(\mathrm{CC}), 5.7 \mathrm{~m} / \mathrm{s}(\mathrm{SR})$ & $3.05 \mathrm{~m} / \mathrm{s}(\mathrm{CC}), 1.4 \mathrm{~m} / \mathrm{s}(\mathrm{SR})$ & $\begin{array}{l}\text { for combustion velocities of } \\
>9.15 \mathrm{~m} / \mathrm{s} \text {, low residence time } \\
\text { causes reduced methane } \\
\text { conversion }\end{array}$ \\
\hline $\begin{array}{l}\text { Catalyst metal properties } \\
\text { surface area factors }\end{array}$ & $1.7(\mathrm{CC}), 1.0(\mathrm{SR})$ & $1.7(\mathrm{CC}), 1.0(\mathrm{SR})$ & $1.7(\mathrm{CC}), 1.0(\mathrm{SR})$ & $\begin{array}{l}\text { SAF values relate catalyst and } \\
\text { geometric surface areas }\end{array}$ \\
\hline $\begin{array}{l}\text { Support properties } \\
\text { pore diameter }\end{array}$ & $500 \mathrm{~nm}$ & $50 \mathrm{~nm}$ & $5000 \mathrm{~nm}$ & $\begin{array}{l}\text { pore diameter increases with } \\
\text { time on stream as the } \\
\text { catalysts sinter }\end{array}$ \\
\hline $\begin{array}{l}\text { primary diffusion } \\
\text { mechanism }\end{array}$ & both & Knudsen & bulk & $\begin{array}{l}\text { the diffusion mechanism } \\
\text { (bulk or Knudsen) is pore- } \\
\text { size-dependent }\end{array}$ \\
\hline
\end{tabular}

${ }^{a}$ Nominal-, improved-, and worst-case calculations are performed for a $9 \mathrm{CR}$ with $k=100 \mathrm{~W} /(\mathrm{m} \mathrm{K})$ and a heat-loss coefficient of $60 \mathrm{~W} /\left(\mathrm{m}^{2} \mathrm{~K}\right)$. For catalyst calculations (CWI, CCI), washcoat properties (thickness, void fraction) are taken from previous experimental work. ${ }^{33,41}$ Combustion channels are indicated by CC.

7.2. Performance Indices as a Function of Scale-Out. Figure $12 \mathrm{a}-\mathrm{d}$ illustrates the performance indices for nominal flow rates (see Table 1) and catalyst properties (see the Supporting Information). Indices are reported as a function of stack size for both adiabatic and laboratory $\left(h=60 \mathrm{~W} /\left(\mathrm{m}^{2} \mathrm{~K}\right)\right)$ heat-loss conditions. All indices are higher under adiabatic conditions, because of higher throughput (VI, CWI, and CCI) and efficiency (EI). For small stacks (3CR and 5CR) with laboratory heat loss, no values are reported in Figure 12, because these stacks are unstable (see Figure 4c).
Figure 12a shows that, generally, the throughput per unit volume (VI) of microsystems is $\sim 2$ orders of magnitude greater than that of the conventional process, which is important for portable and distributed processing. The effects of stack size and heat loss are minor, relative to the effect of throughput (discussed in section 7.3). This same conclusion applies for CWI and CCI, which are also proportional to the throughput. For EI, however, the effects of stack size and heat loss are important. For example, the efficiency of the 7CR under laboratory conditions is $20 \%$ less than that of conventional systems, 

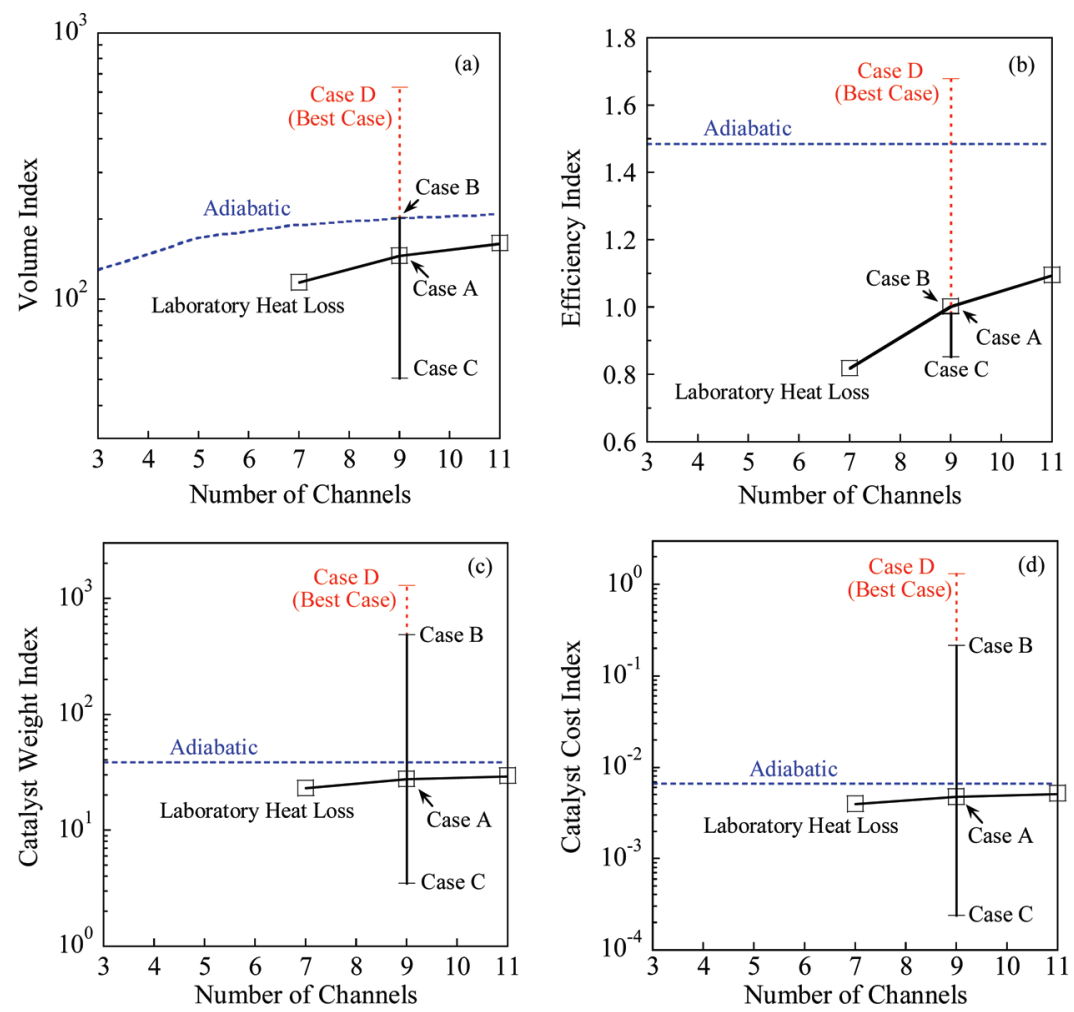

Figure 12. Microchannel stacks compared to a conventional reformer using performance indices. Volume index (a), efficiency index (b), catalyst weight index (c), and catalyst cost index (d) versus size for adiabatic (blue dashed lines) and laboratory (black lines with squares) heat-loss conditions. The sensitivity of indices is indicated for two 9CR cases with laboratory heat loss (solid black error bars; cases A-C) and for a best-case estimate (red dashed error bars; case D). For adiabatic (dashed, blue line) and laboratory heat loss (black line, square symbols), flow rates and catalyst properties are those of case A. Laboratory heat loss corresponds to a heat-loss coefficient of $60 \mathrm{~W} /\left(\mathrm{m}^{2} \mathrm{~K}\right)$. Stack wall thermal conductivity is $100 \mathrm{~W} /(\mathrm{m} \mathrm{K})$.

whereas the $11 \mathrm{CR}$ is $10 \%$ more efficient (see Figure 12b). For most applications entailing many channels, the energy efficiency will be better than that of conventional systems. Performance indices are discussed in more detail next.

7.3. Uncertainty Analysis. Many stack parameters used in computing performance indices change with time and/or operating conditions. In portable applications, hydrogen power output can be in the range of $0 \%-100 \%$ of capacity, depending on instantaneous demand. In previous work, it has been shown that throughput for a single microdevice can vary by an order of magnitude. ${ }^{8}$ In addition to throughput, catalyst metal particle size can vary with synthesis and operating conditions. Of particular importance are calcination and operating temperature. To determine the effect of variability on performance, a simple uncertainty analysis has been conducted.

Three throughput/catalyst property combinations have been considered for a 9CR (cases A, B, and C in Table 2). Variability is estimated for laboratory heat-loss conditions $\left(h=60 \mathrm{~W} /\left(\mathrm{m}^{2}\right.\right.$ $\mathrm{K})$ ) and high-wall thermal conductivity $(100 \mathrm{~W} /(\mathrm{m} \mathrm{K})$ ). Hydrogen power is controlled by varying combustion and SR flow rates while methane conversion in SR channels is kept constant (59\%) for all three cases. Case A (nominal) represents the nominal case presented in the preceding sections of this work (flow rates of Table 1, particle diameter of $100 \mathrm{~nm}$, and support pore size of $500 \mathrm{~nm}$ ). For case B (improved performance), hydrogen power output is high, the catalyst is unsintered with low metal particle diameter $(10 \mathrm{~nm})$ and a reduced washcoat thickness is used (decreased from $100 \mu \mathrm{m}$ to $10 \mu \mathrm{m}$ ). Recently, a method for maintaining low (precious metal alloys) particle size during high-temperature processes was proposed, ${ }^{42}$ so the low diameter used here may be realized under realistic SR conditions. In case C (worst-case), hydrogen power output is low and a sintered catalyst (1000 nm, with $5 \mu \mathrm{m}$ pores) is considered. Catalyst sintering causes a reduction in surface area and increases support pore diameter. Increased pore size changes the diffusion mechanism in the effectiveness factor calculations. Previous work using anodized supports reported a pore diameter of $\sim 50 \mathrm{~nm},{ }^{41}$ which means that internal diffusion is in the Knudsen regime. ${ }^{43}$ However, for highly sintered catalysts, support pores are larger and the internal diffusion mechanism changes (see the Supporting Information).

Results for cases A, B, and C are illustrated with the (solid black) error bars in Figures 12a-d. For these three cases, VI and CWI are always greater than one. This means that, in terms of power output per unit volume or per weight catalyst, microsystems always outperform conventional systems. In terms of cost (CCI), the conclusion is opposite. Conventional systems are preferable to microreactors $(\mathrm{CCI}<1)$, in terms of power output per unit catalyst cost for all three cases, because of the cost of noble metals, relative to nickel. Finally, cases A, B, and $\mathrm{C}$ do not predict a clear winner in terms of efficiency (EI). In case $\mathrm{C}$, the efficiency of conventional systems is higher than that of stacks $(\mathrm{EI}<1)$, whereas in cases A and B, the efficiency of microsystems is higher $(\mathrm{EI}>1)$. This finding implies that details of calculations - specifically, those of the catalyst (size, porous support, loading) - are important and, upon optimization, a higher efficiency may be realized.

In addition to the three cases discussed above, a fourth case is considered (case D). Figure 12b indicates that, to increase efficiency, one must decrease heat loss (and increase stack size if possible). Stack efficiency is also a function of combustion and SR flow rates, and choosing the proper combination to maximize efficiency is nontrivial. Figure S-2 in the Supporting Information shows efficiency as a function of inlet combustion flow rate for the (adiabatic) infinite stack system. For a fixed SR inlet velocity of $0.9 \mathrm{~m} / \mathrm{s}$, the efficiency is highest at low 


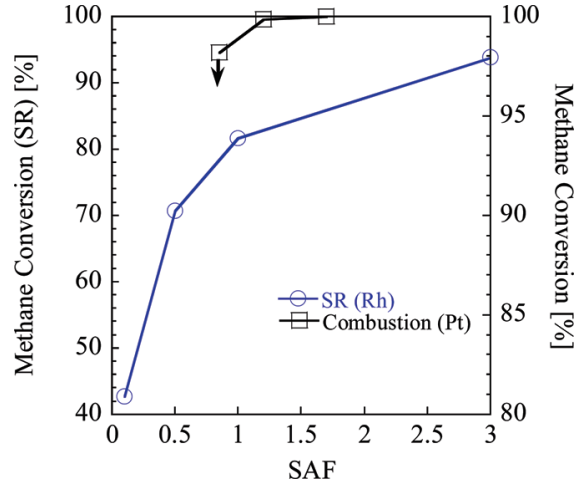

Figure 13. Methane conversion combustion and SR channels, as a function of surface area factor (SAF). Calculations for a wall thermal conductivity of $100 \mathrm{~W} /(\mathrm{m} \mathrm{K})$ and nominal inlet flow rates.

inlet combustion velocities $(1.525 \mathrm{~m} / \mathrm{s})$, because of increased contact time. The resulting maximum efficiency is $65 \%$, which results in an EI value of 1.68 (i.e., stacks are $68 \%$ more efficient that the conventional process). This higher efficiency is a result of higher methane conversion (due to higher temperatures), relative to conventional steam reformers.

Next, a maximum VI value is determined by setting the power output $\left(Q_{\mathrm{H}_{2}}\right)$ to its maximum value (that of the infinite stack, according to Figure S-2 in the Supporting Information) and assuming methane conversion in SR channels is complete $(100 \%)$. These assumptions result in a throughput that is 3.4 times greater than the nominal case (A) and twice as high as the improved case (B), as shown in Figure 12a. Combustion and SR flow rates may not increase beyond these high values, because of blowout. Theoretically, complete SR conversion can be achieved by increasing catalyst loading (Figure 13) or recycling product streams (neither is explicitly studied here).

Higher CCI and CWI values occur when throughput is maximized and the amount of catalyst metal is minimized. The minimum catalyst loading is estimated using SAF values and best-case catalyst properties (case B in Table 2). Reduced SAF values are estimated by determining the minimum catalyst loading for Pt (combustion) and Rh (SR) surfaces by independently varying combustion and SR SAFs in infinite stack simulations (adiabatic, with nominal combustion and SR flow rates). Figure 13 shows the effect of combustion and SR SAFs on methane conversion. For combustion channels, the minimum SAF $(\sim 0.85)$ is the point where combustion fails and stacks do not function. Figure 13 also shows that methane conversion in SR channels decreases nonlinearly with Rh SAF. Even for an order-of-magnitude reduction in Rh SAF (from 1 to 0.1 ), methane conversion is still relatively high (>40\%) and similar to the nominal case (A). These results for Pt and $\mathrm{Rh}$ catalysts suggest that SAF can be reduced by factors of 2 and 10 , respectively, with minimal reduction in throughput. Such reductions in SAF can be achieved by keeping catalyst metal particles small. These lower SAF values $(0.85$ for $\mathrm{Pt}$ and 0.1 for $\mathrm{Rh}$ ) are then used (along with the catalyst properties of case $\mathrm{B}$ and the theoretical maximum power) to calculate values of CWI and CCI (case D). For CWI, this calculation does not change previous conclusions regarding the preference of microtechnology on the basis of catalyst weight. From an economic perspective, microchannel reactors become competitive with conventional systems (i.e., CCI $=1$ ) by simultaneously minimizing the required catalyst loading and maximizing the throughput (Figure 12d). Here, note that, in our analysis, we do not account for the shorter lifetime of the commercial nickel catalyst, compared to rhodium, because of coke formation, which disfavors the economics of the industrial process. Finally, our economic estimates consider only the cost of the catalyst, rather than that of the entire process, which should be included in more-detailed designs.

In summary, the uncertainty analysis performed here is meant to illustrate the variability of the performance indices due to throughput and catalyst properties. Uncertainty can be significant and defines the competitiveness of microtechnology, in terms of efficiency and catalyst cost. In terms of volumetric and gravimetric throughputs, microtechnology always outperforms conventional technology, irrespective of uncertainty.

\section{Conclusions}

In this work, a strategy for scaling out microreactor stacks, which couples exothermic and endothermic processes, is proposed and evaluated for methane steam reforming (SR). Stacks have been evaluated for high-wall and mid-wall thermal conductivities, in terms of efficiency, maximum wall temperature, and stability. Smaller stacks have critical heat-loss coefficients well below typical laboratory values, indicating that

Table 3. Calculations for Cases A, B, and C are Performed for a 9CR with $k=100 \mathrm{~W} /(\mathrm{m} \mathrm{K})$ and a Heat-Loss Coefficient $(h)$ of $60 \mathrm{~W} /\left(\mathrm{m}^{2} \mathrm{~K}\right)$ (Except for the Theoretical Case, Where the 9CR is Adiabatic, To Maximize Indices)

\begin{tabular}{|c|c|c|c|c|c|}
\hline $\begin{array}{l}\text { output parameter } \\
\text { (affected indices) }\end{array}$ & case A (nominal) & case B (improved) & case $\mathrm{C}$ (worst) & $\begin{array}{c}\text { case D (best case) } \\
\text { (indices independently } \\
\text { optimized) }\end{array}$ & comments \\
\hline $\begin{array}{l}\text { methane conversion in } \\
\text { SR channels }\end{array}$ & $58 \%$ & $58 \%$ & $58 \%$ & & $\begin{array}{l}\text { combustion and SR inlet } \\
\text { velocities were chosen } \\
\text { such that total SR } \\
\text { conversion is constant } \\
\text { within the 9CR; } \\
\text { conversion varies for the } \\
\text { theoretical best case }\end{array}$ \\
\hline syngas efficiency (EI) & $39 \%$ & $38 \%$ & $33 \%$ & $65 \%$ & \\
\hline $\begin{array}{l}\text { catalyst support } \\
\text { effectiveness factor, } \\
\eta_{\mathrm{w}}(\mathrm{CCI}, \mathrm{CWI})\end{array}$ & $0.29(\mathrm{CC}), 0.16(\mathrm{SR})$ & $0.86(\mathrm{CC}), 0.66(\mathrm{SR})$ & $0.35(\mathrm{CC}), 0.18(\mathrm{SR})$ & $0.86(\mathrm{CC}), 0.66(\mathrm{SR})$ & $\begin{array}{l}\text { Knudsen and bulk } \\
\text { diffusion are accounted } \\
\text { for (see Supporting Information) }\end{array}$ \\
\hline $\begin{array}{l}\text { required weight loading } \\
\text { (CCI) }\end{array}$ & $2.9 \% \mathrm{Pt}, 1.8 \% \mathrm{Rh}$ & $1 \% \mathrm{Pt}, 0.4 \% \mathrm{Rh}$ & $19.8 \% \mathrm{Pt}, 13.2 \% \mathrm{Rh}$ & $0.5 \% \mathrm{Pt}, 0.04 \% \mathrm{Rh}$ & $\begin{array}{l}\text { weight loading is } \\
\text { calculated using SAF, } \\
\text { support thickness, metal } \\
\text { particle diameter, and } \\
\text { effectiveness factor }\end{array}$ \\
\hline
\end{tabular}

\footnotetext{
${ }^{a}$ The best-case column provides an estimate of output parameter maxima. Correspondingly, these optima output parameters yield maxima in performance indices (see text and Figure 12 for details). Combustion channels are indicated by CC.
} 
these stacks would not function in the laboratory. It is found that stacks with moderate wall thermal conductivities $(23 \mathrm{~W} /(\mathrm{m}$ $\mathrm{K})$ ) are less stable in the presence of heat loss than those with more-conductive walls $(100 \mathrm{~W} /(\mathrm{m} \mathrm{K}))$ under our operating conditions.

Low temperatures in the outermost combustion channel, because of edge heat loss, cause combustion in this channel to cease. For smaller stacks, significant thermal coupling exists between combustion channels and interior combustion channels cannot power the stack alone and ultimately fail as well. In the case of the fifteen-channel reactor (15CR) (the largest stack studied here), thermal coupling is weaker, and for sufficiently high heat-loss coefficients, the interior channels function, despite the failure of the outer combustion channels. For larger stacks, the reaction zone of outer combustion channels expands and partially leaves the stack (blowout). In smaller stacks, the reaction zone in the outer combustion channel is far from the outlet and, therefore, failure is due to extinction. Performance indices are used to compare stacks to conventional technology for adiabatic and laboratory heat-loss conditions. It is found that parallel-plate stacks have volume index and catalyst weight index values that are 1-2 orders of magnitude higher, relative to conventional technology. This is essential for portable and distributed processing and is independent of stack size, heat loss, flow rates and catalyst properties. Heat loss is critical in determining the efficiency of small stacks. Efficiencies of small stacks are approximately equal to those of industrial reformers; however, larger stacks are more efficient. Finally, the cost of nickel (per unit hydrogen production) in the conventional process is, in most cases, at least 1 order of magnitude less than that of microreactors with precious metals. However, our uncertainty indicates that, with optimization of throughput and catalyst (size, catalyst loading, support), it may be possible for microreactors to be cost-competitive with the conventional process.

Our work indicates that scaling-out microreactor stacks can produce highly nonlinear behavior. Fundamentally, this trend is caused by edge heat losses, which affect the outer and inner channels differently. Such nonlinearities cannot be captured with a linear scale-out model and point to the complex behavior of microsystems. Understanding nonlinear behavior can help microtechnology increase its commercial foothold.

\section{Acknowledgment}

This work was supported by the NSF (CBET-072914).

Supporting Information Available: This material is available free of charge via the Internet at http://pubs.acs.org.

\section{Literature Cited}

(1) Wang, Y.; Hu, J. L.; Cao, C. S.; Mazanec, T.; Tonkovich, A. L. Intensification of gas-to-liquid process using microchannel reactors. Abstr. Pap. Am. Chem. Soc. 2004, 227, 90-PETR.

(2) Besser, R. S.; Ouyang, X.; Surangalikar, H. Hydrocarbon hydrogenation and dehydrogenation reactions in microfabricated catalytic reactors. Chem. Eng. Sci. 2003, 58 (1), 19-26.

(3) Benson, R. S.; Ponton, J. W. Process Miniaturization-A Route to Total Environmental Acceptability. Chem. Eng. Res. Des. 1993, 71 (A2), $160-168$.

(4) Jensen, K. F. Microreaction engineering - is small better. Chem. Eng. Sci. 2001, 56 (2), 293-303.

(5) Lerou, J. J.; Harold, M. P.; Ryley, J.; Ashmead, T. C.; O'Brien Johnson, M.; Perrotto, J.; Blaisdell, C. T.; Rensi, T. A.; Nyquist, J. Microfabricated Minichemical Systems: Technical Feasibility. DECHEMA 1996, 132, 51-69.
(6) Norton, D. G.; Deshmukh, S. R.; Wetzel, E. D.; Vlachos, D. G. Downsizing chemical processes for portable hydrogen production. Microreact. Technol. Process Intensif. 2005, 914, 179-193.

(7) Stankiewicz, A. I.; Moulijn, J. A. Process intensification: Transforming chemical engineering. Chem. Eng. Progress 2000, 96 (1), 22-34.

(8) Stefanidis, G. D.; Vlachos, D. G. Millisecond methane steam reforming via process and catalyst intensification. Chem. Eng. Technol. 2008, 31 (8), 1201-1209.

(9) Tonkovich, A. L.; Jarosch, K.; Arora, R.; Silva, L.; Perry, S.; McDaniel, J.; Daly, F.; Litt, B. Methanol production FPSO plant concept using multiple microchannel unit operations. Chem. Eng. J. 2008, 135, S2S8.

(10) Tonkovich, A. L.; Yang, B.; Perry, S. T.; Fitzgerald, S. P.; Wang, Y. From seconds to milliseconds to microseconds through tailored microchannel reactor design of a steam methane reformer. Catal. Today 2007, 120 (1), 21-29.

(11) Venkataraman, K.; Wanat, E. C.; Schmidt, L. D. Steam reforming of methane and water-gas shift in catalytic wall reactors. AIChE J. 2003, 49 (5), 1277-1284.

(12) Zanfir, M.; Gavriilidis, A. Catalytic combustion assisted methane steam reforming in a catalytic plate reactor. Chem. Eng. Sci. 2003, 58 (17), 3947-3960.

(13) Stefanidis, G. D.; Vlachos, D. G.; Kaisare, N. S.; Maestri, M. Methane Steam Reforming at Microscales: Operation Strategies for Variable Power Output at Millisecond Contact Times. AIChE J. 2009, 55 (1), 180191.

(14) O’Connell, M.; Kolb, G.; Schelhaas, K. P.; Schuerer, J.; Tiemann, D.; Ziogas, A.; Hessel, V. Development and evaluation of a microreactor for the reforming of diesel fuel in the $\mathrm{kW}$ range. Int. J. Hydrogen Energy 2009, 34 (15), 6290-6303.

(15) Besser, R. S. Microdevice-based system for catalyst development. Chem. Eng. Commun. 2003, 190 (10), 1293-1308.

(16) Tonkovich, A.; Kuhlmann, D.; Rogers, A.; McDaniel, J.; Fitzgerald, S.; Arora, R.; Yuschak, T. Microchannel technology scale-up to commercial capacity. Chem. Eng. Res. Des. 2005, 83 (A6), 634-639.

(17) Amador, C.; Gavriilidis, A.; Angeli, P. Flow distribution in different microreactor scale-out geometries and the effect of manufacturing tolerances and channel blockage. Chem. Eng. J. 2004, 101 (1-3), 379-390.

(18) Commenge, J. M.; Falk, L.; Corriou, J. P.; Matlosz, M. Optimal design for flow uniformity in microchannel reactors. AIChE J. 2002, 48 (2), 345-358.

(19) Delsman, E. R.; Pierik, A.; De Croon, M.; Kramer, G. J.; Schouten, J. C. Microchannel plate geometry optimization for even flow distribution at high flow rates. Chem. Eng. Res. Des. 2004, 82 (A2), 267-273.

(20) Cremers, C.; Pelz, A.; Stimming, U.; Haas-Santo, K.; Gorke, O.; Pfeifer, P.; Schubert, K. Micro-structured methane steam reformer with integrated catalytic combustor. Fuel Cells 2007, 7 (2), 91-98.

(21) Delsman, E. R.; Laarhoven, B.; de Croon, M.; Kramer, G. J.; Schouten, J. C. Comparison between conventional fixed-bed and microreactor technology for a portable hydrogen production case. Chem. Eng. Res. Des. 2005, 83 (A9), 1063-1075.

(22) Deshmukh, S. R.; Vlachos, D. G. CFD simulations of coupled, countercurrent combustor/reformer microdevices for hydrogen production. Ind. Eng. Chem. Res. 2005, 44 (14), 4982-4992.

(23) Kolios, G.; Glockler, B.; Gritsch, A.; Morillo, A.; Eigenberger, G. Heat-integrated reactor concepts for hydrogen production by methane steam reforming. Fuel Cells 2005, 5 (1), 52-65.

(24) Srinivasan, R.; Hsing, I. M.; Berger, P. E.; Jensen, K. F.; Firebaugh, S. L.; Schmidt, M. A.; Harold, M. P.; Lerou, J. J.; Ryley, J. F. Micromachined reactors for catalytic partial oxidation reactions. AIChE J. 1997, 43 (11), 3059-3069.

(25) Rostrup-Nielsen, J. R.; Rostrup-Nielsen, T. Large-scale hydrogen production. CATTECH 2002, 6 (4), 150-159.

(26) Rostrup-Nielsen, J. R. Catalytic Steam Reforming. In Catalysis, Science and Technology, 5th ed.; Boudart, J. R. A. a. M., , Ed.; Springer: Berlin, 1984; Vol. 5, p 1.

(27) Tonkovich, A. Y.; Perry, S.; Wang, Y.; Qiu, D.; LaPlante, T.; Rogers, W. A. Microchannel process technology for compact methane steam reforming. Chem. Eng. Sci. 2004, 59 (22-23), 4819-4824.

(28) FLUENT 6.1; ANSYS: Lebanon, NH, 2003.

(29) Maestri, M.; Vlachos, D. G.; Beretta, A.; Groppi, G.; Tronconi, E. Steam and dry reforming of methane on Rh: Microkinetic analysis and hierarchy of kinetic models. J. Catal. 2008, 259 (2), 211-222.

(30) Deshmukh, S. R.; Vlachos, D. G. A reduced mechanism for methane and one-step rate expressions for fuel-lean catalytic combustion of small alkanes on noble metals. Combust. Flame 2007, 149 (4), 366-383.

(31) Kaisare, N. S.; Deshmukh, S. R.; Vlachos, D. G. Stability and performance of catalytic microreactors: Simulations of propane catalytic combustion on Pt. Chem. Eng. Sci. 2008, 63 (4), 1098-1116. 
(32) Sandler, S. I., Chemical, Biochemical, and Engineering Thermodynamics, 4th ed.; John Wiley \& Sons: New York, 2006; p 946.

(33) Norton, D. G.; Wetzel, E. D.; Vlachos, D. G. Thermal management in catalytic microreactors. Ind. Eng. Chem. Res. 2006, 45 (1), $76-$ 84.

(34) Federici, J. A.; Wetzel, E. D.; Geil, B. R.; Vlachos, D. G. Single channel and heat recirculation catalytic microburners: An experimental and computational fluid dynamics study. Proc. Combust. Inst. 2009, 32, 30113018.

(35) Green, D. W.; Perry, R. H. Perry's Chemical Engineers' Handbook, 8th ed.; McGraw-Hill: New York, 2007.

(36) Ritter, M. SiC Quotation from Morgan Advanced Ceramics, Inc., 2010.

(37) Kaisare, N. S.; Vlachos, D. G. Optimal reactor dimensions for homogeneous combustion in small channels. Catal. Today 2007, 120 (1), 96-106.

(38) Federici, J. A.; Vlachos, D. G. A computational fluid dynamics study of propane/air microflame stability in a heat recirculation reactor. Combust. Flame 2008, 153 (1-2), 258-269.

(39) Norton, D. G.; Vlachos, D. G. A CFD study of propane/air microflame stability. Combust. Flame 2004, 138 (1-2), 97-107.
(40) Plehiers, P. M.; Froment, G. F. Coupled Simulation of Heat Transfer and Reaction in a Steam Reforming Furnace. Chem. Eng. Technol. 1989, 1989 (12), 20-26.

(41) Federici, J. A.; Norton, D. G.; Bruggemann, T.; Voit, K. W.; Wetzel, E. D.; Vlachos, D. G. Catalytic microcombustors with integrated thermoelectric elements for portable power production. J. Power Sources 2006, 161 (2), 1469-1478.

(42) Cao, A.; Veser, G. Exceptional high-temperature stability through distillation-like self-stabilization in bimetallic nanoparticles. Nat. Mater. 2010, 9 (1), 75-81.

(43) Froment, G. F.; Bischoff, K. B. Chemical Reactor Analysis and Design; John Wiley \& Sons: New York, 1990.

(44) Stefanidis, G. D.; Vlachos, D. G. High vs. low temperature reforming for hydrogen production via microtechnology. Chem. Eng. Sci. 2009, 64 (23), 4856-4865.

Received for review March 1, 2010 Revised manuscript received May 20, 2010 Accepted May 24, 2010

IE100459B 